\title{
"Aproximación metodológica al análisis de contenidos a partir del discurso de los actores. Un ensayo de investigación social de procesos de desarrollo local (Loja, Ecuador)"
}

\author{
"A methodological approach to content analysis based on the \\ actors' discourse. A social research study on local development \\ processes (Loja, Ecuador)"
}

\author{
Diana Mendieta Vicuña \\ Universidad de Valencia \\ Javier Esparcia Pérez \\ Universidad de Valencia \\ Javier.esparcia@uv.es (ESPAÑA)
}

Recibido: 21.122016

Aceptado: 03.11.2017

\section{RESUMEN}

El análisis de contenidos está en el centro de gran cantidad de estudios de investigación social. Por su parte, el análisis del sistema de actores también ha sido ampliamente explotado en el estudio de procesos de desarrollo local, bajo diferentes aproximaciones. Sin embargo, este trabajo tiene como objetivo mostrar algunas de las potencialidades y ventajas del análisis de contenidos a partir del discurso de los actores implicados en procesos de desarrollo local. Para ello, se toma como punto de partida la información primaria obtenida de las entrevistas semiestructuradas realizadas a una muestra de actores sociales, económicos e institucionales vinculados a la puesta en marcha de la central eólica Villonaco (Loja, Ecuador). Según el gobierno ecuatoriano, esta ha de tener una clara proyección en el desarrollo local, y de ahí el interés por analizar estos procesos desde esta perspectiva metodológica. Para mostrar las potencialidades del análisis de contenidos a partir del discurso de los actores se utiliza el software MAXQDA, que permite, tras la codificación de la información, analizar los diferentes temas y subtemas que definen las posiciones y valoraciones de los actores implicados. 


\title{
PALABRAS CLAVE
}

Análisis de contenidos, sistema de actores; metodología cualitativa; desarrollo local; Loja (Ecuador).

\begin{abstract}
The content analysis is at the core of a large number of social studies. On the other hand, the stakeholder analysis has been widely used in the study of local development processes from different approaches. However, this paper aims to show the potential and advantages of content analysis based on the actors' discourse involved in local development processes. Primary information obtained from interviews conducted with a sample of social, economic and institutional actors linked to the starting up and operation of Villonaco Wind Farm (Loja, Ecuador), has been taken as a starting point. According to the Ecuadorian government, this wind farm should have a clear projection in local development, hence the interest in the analysis of these processes using this methodological approach. Software MAXQDA is used to show the potential of content analysis. This tool allows, after the encoding process of information, to analyze the various topics and subtopics that define the positions adopted by the actors and their appraisals of the studied processes.
\end{abstract}

\section{KEY WORDS}

Content analysis, stakeholder analysis; qualitative methodology; local development; Loja (Ecuador).

\section{INTRODUCCIÓN}

Los procesos de desarrollo local suelen caracterizarse por una elevada complejidad, lo cual con frecuencia dificulta un análisis comprehensivo de los mismos. Son diversos los enfoques que permiten aproximarse a esa complejidad, destacando aquellos que toman en cuenta el papel protagonista de los actores de tales procesos (lo que podemos considerar como sistema de actores vinculados al desarrollo local de un territorio). En este contexto, la hipótesis que se plantea en esta investigación es que la aproximación metodológica del análisis de contenidos (a partir del discurso de los actores), ofrece resultados válidos y adecuados para entender las dinámicas de desarrollo local. Diferentes trabajos ponen de relieve la utilidad del análisis de contenidos (Piñuel, 2002; Krippendorff, 2004; Kohlbacher, 2006; Kaefer et al., 2015; Lima y Manini, 2016; Stamann et al., 2016). Algunos de ellos se refieren concretamente a su aplicación a casos de estudio como estrategia de investigación, como se hace en este trabajo. Más próximos resultan otros trabajos que aplican directamente el análisis de contenidos al 
estudio de procesos o acciones vinculadas al desarrollo local. Así por ejemplo, en algunos trabajos se analizan las buenas prácticas en desarrollo local en zonas rurales, a partir de los conceptos clave que las identifican (Esparcia, 2010); por su parte, en otros se analizan los contenidos derivados del discurso de los actores sobre procesos de desarrollo local en zonas rurales en España (Camacho y Esparcia, 2014) ${ }^{1}$.

El trabajo que aquí se presenta forma parte de una investigación más amplia $^{2}$, en la que se analizan con detalle los procesos de desarrollo local en la zona de influencia de la central eólica Villonaco (Ecuador). Dado que no se dispone de un elevado número de trabajos que apliquen el análisis de contenidos al estudio de procesos de desarrollo local, testar su utilidad forma parte del propio diseño de la investigación. En consecuencia, el objetivo fundamental de la investigación que aquí se presenta es testar e ilustrar el potencial del enfoque metodológico del análisis de contenidos a partir de entrevistas al sistema de actores. El análisis detallado de los resultados en cuanto a los procesos de desarrollo local presentes en el área de estudio se abordará, por tanto, con posterioridad a esta investigación.

Resulta novedoso y, por tanto, de interés, no solo testar esta aproximación metodológica en el ámbito de los procesos de desarrollo local, sino el que ello se lleve a cabo con relación a procesos vinculados a una central eólica. En efecto, la reciente normativa ecuatoriana sobre centrales eléctricas establece la obligatoriedad de fomentar y apoyar los procesos de desarrollo local en su zona de influencia. Esta obligatoriedad constituye una novedad respecto de lo que han venido siendo este tipo de iniciativas, y pretende situar a las nuevas centrales eléctricas ecuatorianas en un contexto de mayor aproximación a los principios del desarrollo sostenible.

El caso de estudio que se ha seleccionado es la zona de influencia del Parque Eólico Villonaco (Provincia de Loja, Ecuador), delimitada por la empresa de generación de electricidad, Corporación Eléctrica del Ecuador - Unidad de Negocio GENSUR (CELEC EP GENSUR). Esta zona comprende diez barrios cercanos a esta central (Figura 1). En este territorio, la empresa CELEC EP GENSUR ha diseñado, y actualmente implementa, un Plan de Desarrollo Territorial Comunitario (PDTC) que es (o pretende ser) un instrumento para el desarrollo local. Este Plan es el resultado de la directriz del Ministerio de Electricidad y Energía Renovable (MEER), que pretende promover el desarrollo económico y social en las zonas de influencia de los nuevos proyectos de generación de electricidad, desde su construcción y durante su operación comercial.

${ }^{1}$ En parte aquí se sigue la idea de este trabajo, en el que los autores aplican el análisis de contenidos a partir del discurso de un conjunto diverso de actores (recogido en entrevistas semiestructuradas), vinculados a procesos de desarrollo local. No obstante, los autores están más centrados en construir un sistema de códigos válido para abordar el desarrollo rural en España, desde el enfoque metodológico del análisis de contenidos, y no tanto en la aplicación de otras herramientas de análisis, que sí se desarrollan en nuestra investigación.

2 Proyecto Energías Renovables y Desarrollo Local (Loja - Ecuador). 


\section{Figura 1. Localización del Parque eólico Villonaco y su zona de influencia}

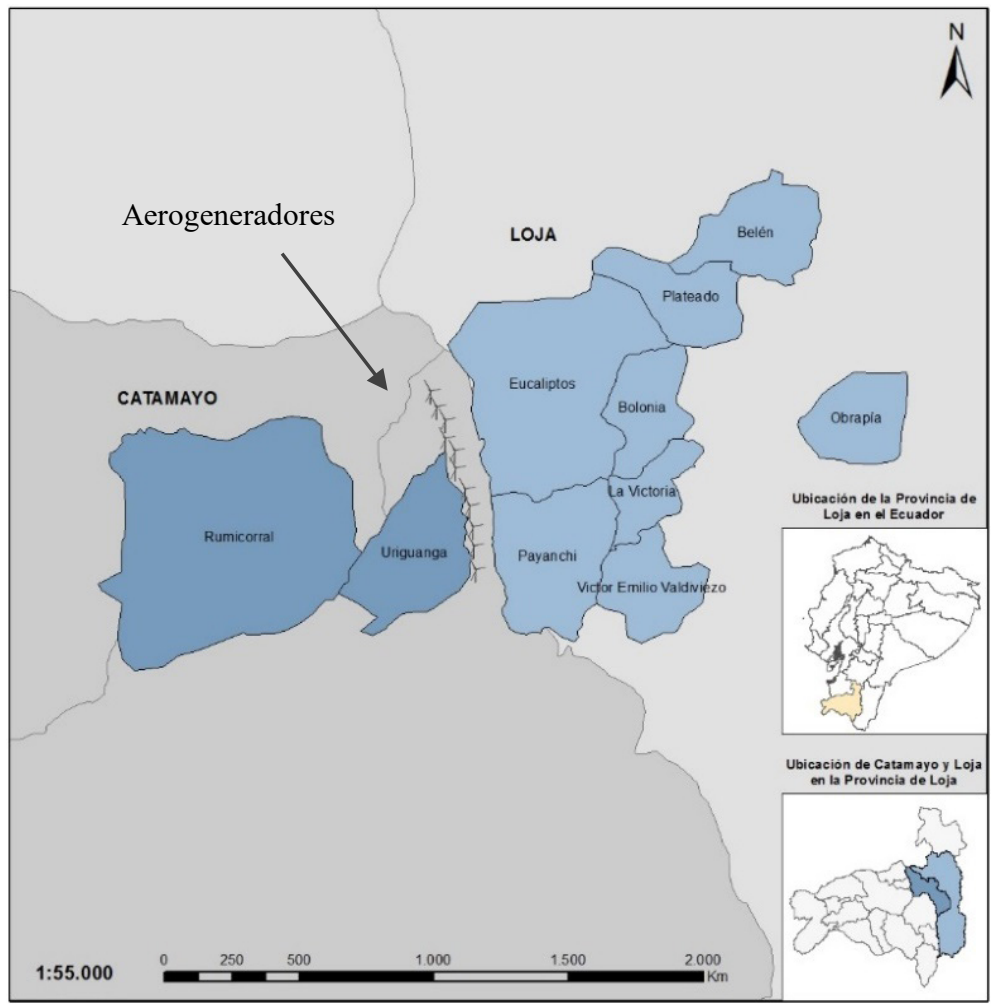

Fuente: CELEC EP GENSUR y elaboración propia.

Tras esta primera sección introductoria, en la segunda se presentan la metodología y las fuentes que derivan del diseño de la investigación; en la tercera se reflexiona sobre la utilidad de trabajar con el sistema de actores como objeto de estudio en la investigación social referida a procesos de desarrollo local. La cuarta sección tiene un importante contenido metodológico, como corresponde a una investigación centrada en testar una aproximación metodológica que toma como punto de partida el discurso de los actores; de esta forma, se detalla y analiza la estructura de la entrevista y se define y explica el sistema de categorías y el proceso de codificación de la información. La quinta sección se dedica a la presentación y discusión de los resultados obtenidos. El artículo finaliza con una sección dedicada a presentar las principales conclusiones. 


\section{METODOLOGÍA Y FUENTES}

La primera aproximación al tema y área de estudio se ha realizado, además de la bibliografía, a partir de fuentes documentales provenientes de organismos oficiales (páginas web, planes de desarrollo local, informes de rendición de cuentas, etc.), y medios de comunicación local y nacional. Esta información ha servido para conocer las intervenciones planeadas o en fase de implementación en el marco de los procesos de desarrollo local, identificar a los actores involucrados (tanto los responsables de su ejecución como los representantes de los principales beneficiarios). Ese primer estudio exploratorio permite definir con mayor precisión las temáticas y actores clave en el caso concreto de estudio. No obstante, para el análisis de los procesos de desarrollo local es muy útil trabajar con fuentes primarias y generar investigación empírica a partir de las visiones de quienes están "dentro" de la realidad estudiada (Kvale, 2011). Además, la interlocución con los actores clave constituye una forma adecuada para obtener información cualitativa de especial valor (Verd y Lozares, 2016).

Hay diversas aproximaciones para obtener esa información primaria. Así, los grupos focales podrían resultar útiles dado que la interacción entre los participantes estimula a compartir diferentes ideas respecto al tema de estudio, y permite contrastar posiciones, todo ello con un coste temporal reducido (Morgan, 1997; Barbour, 2013). Sin embargo, hay aspectos que pueden limitar la calidad de la información obtenida, como la idiosincrasia de la población local y, sobre todo, las diferencias sociales entre los participantes (Blau y Schwartz, 1984; Bourdieu, 1989), que pueden traducirse en posiciones de poder (Halfacree et al., 2002; Esparcia et al., 2015) y manifestarse en la propia sesión de trabajo. En nuestra investigación todos estos condicionamientos han aconsejado descartar los grupos focales (Stewart y Shamdasani, 2015).

Como consecuencia se ha optado por la entrevista semiestructurada como método de recogida de información primaria más adecuado, que permite superar los citados condicionamientos y a la vez mantener una elevada calidad, todo ello pese al coste significativamente mayor para su obtención. Efectivamente, la información obtenida a través de las entrevistas permite aproximarse a la forma de entender la realidad por parte del entrevistado (Valles, 2014), así como generar conocimiento empírico (Kvale, 2011) respecto a las especificidades locales que generan iniciativas de desarrollo territorial (Arocena, 2001). Todo ello, sumado a los criterios de diversidad en cuanto a origen territorial y actividades de los actores, enriquece el posterior análisis de la información, sobre todo a la hora de establecer comparaciones y coincidencias entre las diferentes perspectivas de los entrevistados. En el diseño de la investigación se ha de tener en cuenta la representatividad de la muestra, en nuestro caso con relación, por un lado, a los territorios (barrios) y la diversidad de actores locales involucrados en los procesos de desarrollo y, por otro, a los representantes de entidades externas implicadas en la iniciativa. Como resultado se ha obtenido una muestra total de 32 actores (cuya composición se detalla en la siguiente sección).

En la entrevista se contempla un conjunto de temas que responden a los 
objetivos de la investigación. El carácter semiestructurado de la misma permite mantener la coherencia y centrar el discurso de los actores en las diferentes temáticas relacionadas con los procesos de desarrollo local y su impacto en el área. Aunque el uso de este instrumento puede generar ciertas dudas respecto al tratamiento de las verdaderas preocupaciones de los actores (Corbin y Strauss, 2015), el investigador, sin perder de vista el objetivo de estudio, ha de ser lo suficientemente flexible como para permitir (y en su caso, estimular) que los informantes expresen abiertamente los asuntos que les preocupan y que puedan ser de interés para la investigación.

A partir de aquí, el análisis cualitativo de la información primaria (Ruiz, 2012; Taylor et al., 2016) permite dar respuesta a los interrogantes (hipótesis de investigación) planteados con relación, en este caso, a los procesos de desarrollo local presentes en el territorio. Una primera estrategia de análisis se centraría en la formulación de tipologías extraídas del discurso de los actores, con el fin de lograr una imagen estructurada de tales discursos. Sin embargo, más allá de la descripción tipológica, una estrategia complementaria se centra en un análisis de las relaciones entre los diferentes elementos de los discursos de los actores (Krause, 1995). La riqueza de esta información radica en el conjunto de recursos cognitivos que, producidos en el contexto social, geográfico e histórico de nuestra investigación, representan de manera más fiel la realidad social del fenómeno que se está estudiando (Keller, 2010).

En el marco de esta estrategia, más elaborada, el proceso de organización y tratamiento de la información presenta cuatro grandes fases (Figura 2). La primera consiste en la definición de los temas centrales que serán planteados a los diferentes actores durante la entrevista. Estos temas presentan a su vez preguntas de apoyo que podrán derivar en subtemas. En la segunda fase, tras la realización de estas y su posterior transcripción, se lleva a cabo un análisis sistemático del texto, basado en un proceso de agregación de la información obtenida. Por tanto, temas y subtemas se convierten en lo que algunos autores denominan definición deductiva de categorías y subcategorías (Kuckartz, 2014). La equivalencia entre temas-subtemas y categorías-subcategorías suele ser muy elevada, pero no necesariamente siempre es completa. La construcción de categorías y subcategorías supone la combinación de los enfoques deductivo e inductivo, dado que también se utilizan las ideas que surgen de la información empírica que aportan los entrevistados (Mayring, 2000). Esta puede suponer nuevas perspectivas o precisiones que contribuyan a profundizar y, en su caso, redefinir, los temas iniciales, generando esas nuevas categorías y subcategorías que, por ello, no tienen por qué corresponderse totalmente con los temas y subtemas inicialmente planteados. 


\section{Figura 2. Proceso de organización y tratamiento de la información}

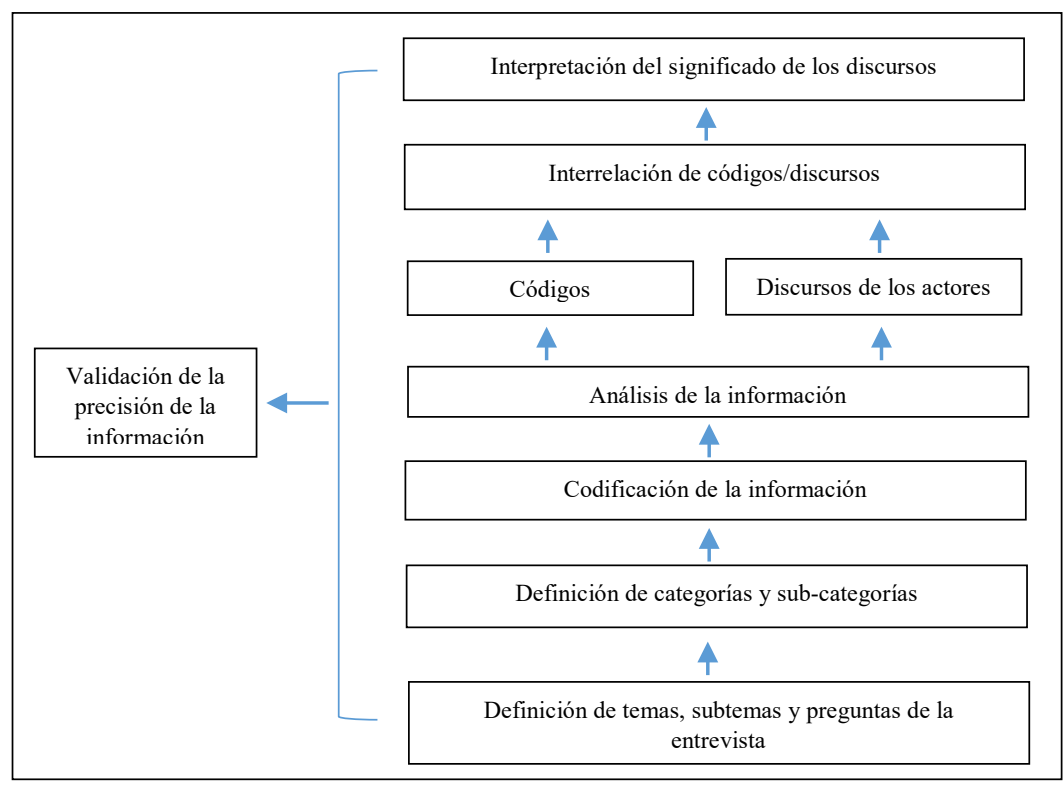

Fuente: Elaborado a partir de Creswell, 2014: 197

La tercera fase consiste en estructurar la información para su tratamiento, es decir, la identificación de cada segmento de texto con un código o subcódigo. Habitualmente los códigos y subcódigos resumen las categorías y subcategorías, para hacerlas manejables en el análisis textual. Se deduce de lo anterior que el manejo de la información se lleva a cabo a partir del sistema de códigos y subcódigos, que ha de ser lo suficientemente preciso como para reflejar de manera diferenciada todos los contenidos que el investigador considere que son relevantes. Si la definición de categorías y subcategorías se ha llevado a cabo adecuadamente, el sistema de códigos y subcódigos constituirá un fiel reflejo de aquellas. No obstante, siempre es necesario testarlo previamente a su aplicación, aplicándolo a una muestra suficiente y representativa de entrevistas. En nuestro caso se aplicó a una cuarta parte de las entrevistas en las que se encontraban representados los diferentes grupos de actores ${ }^{3}$. Por último, tras la codificación de la información, la cuarta y última fase, que implica un mayor nivel de complejidad (Junker, 2012), consiste en el análisis de la información (Creswell, 2014), buscando las conexiones y relaciones que permitan la interpretación y explicación de los discursos de los actores entrevistados.

3 Así, la cuarta parte corresponde a ocho entrevistas, que se han distribuido entre tres actores institucionales, dos actores de carácter económicos, y tres actores sociales. 
Para almacenar, organizar, procesar, y analizar la información obtenida, se ha optado por el software de análisis de datos cualitativos MAXQDA (v.12), principalmente por su versatilidad y utilidad a la hora de gestionar y facilitar la sistematización de la información en categorías y subcategorías (que se reflejarán en códigos y subcódigos en el software) (Ku囚 Saillard, 2011; Silver y Lewins, 2014). Sin olvidar las necesarias cautelas al utilizar este tipo de instrumentos (Junker, 2012), el trabajo con el software tiene muchas otras ventajas, también de orden práctico, como la posibilidad de ponderar la importancia u orientación de determinada argumentación codificada (White et al., 2012)4. En nuestro caso se ha restringido a valorar la posición de los actores (favorable, neutra o desfavorable) ante determinadas intervenciones públicas.

Además de que su empleo resulta innovador en este tipo de estudios (como se señala en el trabajo de Camacho y Esparcia, 2014), su funcionalidad permite el análisis de resultados a partir de diferentes herramientas (filtro, matrices, retratos de documentos, etc.) y criterios (proporción de entrevistas en las que está presente una categoría o subcategoría temática y la relación o concurrencia entre ellas). Estas herramientas son especialmente útiles para identificar la tipología de discurso y la importancia que los distintos grupos de actores otorgan a las temáticas planteadas en la entrevista. Algunas de las herramientas más útiles para el análisis de la información se presentan en las siguientes secciones. Como paso previo, en la próxima sección, abordaremos cuestiones relacionadas con la definición del sistema de actores y su tratamiento.

\section{EL ANÁLISIS DEL SISTEMA DE ACTORES}

\subsection{Los actores en los procesos de desarrollo local}

El análisis del sistema de actores permite una aproximación muy útil al estudio de los procesos de desarrollo local: "cualquier individuo, grupo social o institución interesado en el desarrollo de un territorio" (FAO, 2005: 31) puede considerarse como un actor en ese sistema, en el cual cumple una función, actúa desde una determinada posición, interactúa con otros actores, y todo ello da lugar a relaciones de dependencia y dominancia (que en parte constituyen la base para mecanismos de reproducción social que pueden estar presentes en el seno de ese sistema).

Es importante tener en cuenta que los discursos de los actores "contienen este conocimiento de la realidad social" (Ruiz Ruiz, 2009: 39) que resulta fundamental para un análisis preciso de los procesos de desarrollo local. Por

${ }^{4}$ Los autores ponen de relieve la utilidad de los instrumentos analíticos basados en software para el análisis de datos cualitativos (Qualitative Data Analysis Software - QDAS), y en particular su aplicación de cara a la utilización de métodos mixtos, como es el análisis de conjuntos de datos cualitativos basados en entrevistas a actores (de forma que permiten la combinación de resultados de un análisis cualitativo de contenidos con análisis estadísticos de datos asociados o derivados). 
otro lado, los saberes contenidos en estos discursos constituyen "el espacio en el que el sujeto puede tomar posición para hablar de los objetos de que trata su discurso" (Foucault, 1978: 306), que puede ser entendido como "cualquier práctica [social] por la que los sujetos dotan de sentido a la realidad" (Ruiz Ruiz, 2009: 3).

Por tanto, los discursos ponen de relieve la posición y la manera en la que cada actor percibe el objeto de estudio, y constituyen un recurso adecuado para analizar cualitativamente los procesos, prácticas y políticas públicas (Keller, 2010). En consecuencia, a partir de la identificación de los actores, la definición de sus características (intereses, conocimientos, espacios de poder, control de recursos, etc.), y el análisis de sus discursos, es posible valorar su percepción sobre los efectos que se derivan de determinadas intervenciones. Así, el análisis del sistema de actores constituye una aproximación adecuada para abordar aspectos menos tangibles (Yang et al., 2015), permitiendo identificar los problemas y las potencialidades de estrategias locales, facilitando la comprensión y análisis de la realidad económica y social.

El sistema de actores locales ha sido ampliamente utilizado en el análisis de los procesos de desarrollo local, de su diagnóstico, del diseño de estrategias de intervención, y hasta en la propia implementación de diferentes acciones. En primer lugar, constituye la base de metodologías de investigación-acción participativa (IAP), en las que se involucra tanto a los investigadores como a la población destinataria de intervenciones o programas de desarrollo (Fals Borda y Rodríguez Brandão, 1986; Villasante et al., 2000; Alberich et al., 2009). Como paso previo es útil realizar un mapeo de actores o "sociograma", identificando tanto a los actores relevantes como las relaciones entre ellos (Villasante, 2007, 2015; Alberich 2014).

En segundo lugar, otro tipo de aproximación útil en procesos de desarrollo local que toma como punto de partida el sistema de actores se basa en el enfoque del marco lógico, orientado sobre todo al diagnóstico y a la planificación de proyectos o intervenciones (Aldunate y Córdoba, 2011). En tercer lugar, el análisis de los contenidos del discurso de los actores constituye otra aproximación válida y útil, especialmente cuando no se persigue la planificación de proyectos o intervenciones. En este caso el objetivo es más modesto, y se restringe al análisis detallado de los procesos de desarrollo desde la perspectiva de los actores, incluyendo en su caso, el estudio del impacto o efectos de políticas o programas de intervención. Como se ha avanzado, esta es la aproximación que responde de manera más adecuada a los objetivos de la presente investigación. Efectivamente, el análisis de los discursos (a partir del enfoque de contenidos) puede ser especialmente útil porque permite analizar tanto los efectos esperados por los destinatarios de las políticas e iniciativas públicas como la visión de los responsables de la implementación de tales políticas e iniciativas.

Esta visión, a través del discurso de los actores, también puede ser fundamental a la hora de diseñar intervenciones o estrategias de desarrollo, porque permite tomar como punto de partida un diagnóstico y una detección de fortalezas y debilidades desde el propio territorio. Consecuentemente, en este ejemplo 
de investigación de procesos de desarrollo local adquiere una gran importancia la definición de quiénes componen el sistema de actores. Este aspecto se aborda en el apartado siguiente.

\subsection{El sistema de actores en el caso de estudio}

De cara a una primera delimitación del sistema de actores cabe hacerse una serie de preguntas, y diferenciar, al menos, tres grandes sectores. Por un lado, la población potencialmente afectada o beneficiada por la central eólica y el PDTC (población local y sector privado); por otro, aquellos actores vinculados al diseño, financiación y ejecución de las intervenciones (administraciones públicas) (Cuadro 1).

Cuadro 1. Identificación inicial del sistema de actores

\begin{tabular}{|c|c|c|c|c|}
\hline \multirow{2}{*}{\multicolumn{2}{|c|}{ Preguntas clave }} & \multicolumn{3}{|c|}{ Actores } \\
\hline & & \multirow{2}{*}{$\begin{array}{c}\begin{array}{c}\text { Población } \\
\text { local }\end{array} \\
\mathbf{X} \\
\end{array}$} & \multirow{2}{*}{$\begin{array}{c}\begin{array}{c}\text { Sector } \\
\text { privado }\end{array} \\
\mathbf{X} \\
\end{array}$} & \multirow{2}{*}{$\begin{array}{c}\text { Administraciones } \\
\text { públicas }\end{array}$} \\
\hline 1 & $\begin{array}{l}\text { ¿Quiénes son los posibles } \\
\text { beneficiarios de la central eólica? }\end{array}$ & & & \\
\hline 2 & $\begin{array}{l}\text { ¿Quiénes se pueden ver afectados } \\
\text { negativamente por la central? }\end{array}$ & $\mathbf{X}$ & $\mathbf{X}$ & \\
\hline 3 & $\begin{array}{l}\text { ¿Ha habido, y se han identificado, } \\
\text { sectores opuestos a la central? }\end{array}$ & $\mathbf{X}$ & $\mathbf{X}$ & \\
\hline 4 & $\begin{array}{l}\text { ¿Qué empresas suministran } \\
\text { bienes y servicios a la central? }\end{array}$ & & $\mathbf{X}$ & \\
\hline 5 & $\begin{array}{l}\text { ¿Qué entidad define la política de } \\
\text { desarrollo local? }\end{array}$ & & & $\mathbf{X}$ \\
\hline 6 & $\begin{array}{l}\text { ¿Qu ién fi n a n cia las } \\
\text { intervenciones? }\end{array}$ & & & $\mathbf{X}$ \\
\hline 7 & $\begin{array}{l}\text { ¿Quién es el responsable de } \\
\text { su ejecución en la zona de } \\
\text { influencia? }\end{array}$ & & & $\mathbf{X}$ \\
\hline 8 & $\begin{array}{l}\text { ¿Quiénes son los principales } \\
\text { beneficiarios de las } \\
\text { intervenciones? }\end{array}$ & $\mathbf{X}$ & $\mathbf{X}$ & \\
\hline
\end{tabular}

Fuente: Elaboración propia a partir de estudio exploratorio del PDTC y trabajo de campo. Proyecto Energías Renovables y Desarrollo Local (Loja - Ecuador).

A su vez, el modelo de gestión en el marco del cual se realizan las intervenciones en la zona de influencia de la central permite definir tres grandes tipos de actores institucionales: el responsable de la definición de la política energética; aquellos que financian las intervenciones; $y$, finalmente, las entidades encargadas de ejecutar las intervenciones del PDTC, con funciones diversas. Como resultado, en la muestra de actores institucionales están representadas todas las 
entidades públicas involucradas (Cuadro 2).

Otra parte importante del sistema de actores está conformado por los diferentes beneficiarios potenciales. A efectos del análisis de las dinámicas locales de desarrollo, se han diferenciado, por un lado, los actores con funciones principalmente económicas (sector privado) y, por otro, los actores con un perfil marcadamente social, en gran parte representantes de la sociedad civil. En el primer caso están los proveedores de bienes y servicios para la central (servicios de limpieza y jardinería), así como otros beneficiarios de las intervenciones para el desarrollo productivo de la zona (productores autónomos y asociación de agricultores).

Por su parte, en este trabajo se identifican como actores sociales relevantes a los presidentes de los barrios de la zona de influencia (por ser representantes y portavoces del conjunto de vecinos y a la vez interlocutores directos con los demás actores), así como los presidentes de los comités de gestión del agua (por las funciones de liderazgo que ejercen en sus respectivas comunidades y por la importancia que tienen estas asociaciones como estructuras organizativas de la población), y, finalmente, a los directores y comités de padres de familia de los cinco centros educativos beneficiados con las obras implementadas para la mejora del equipamiento educativo. En conjunto, se delimitó una muestra de 32 actores, con los que se han mantenido entrevistas personales entre diciembre de 2014 y marzo de 2015.

\section{Cuadro 2. Principales actores locales y número de entrevistas realizadas}

\begin{tabular}{|c|c|c|c|}
\hline & \\
\hline \multirow{5}{*}{ 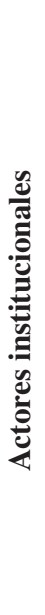 } & $\begin{array}{l}\text { Política } \\
\text { energética }\end{array}$ & Ministerio de Electricidad y Energía Renovable & \multirow{5}{*}{12} \\
\hline & $\begin{array}{l}\text { Financiación de } \\
\text { actuaciones }\end{array}$ & $\begin{array}{l}\text { Corporación Eléctrica del Ecuador CELEC EP GENSUR } \\
\text { (Empresa de generación de electricidad)) }\end{array}$ & \\
\hline & \multirow[b]{3}{*}{$\begin{array}{l}\text { Ejecución de } \\
\text { obras }\end{array}$} & Corporación Eléctrica del Ecuador - CELEC EP GENSUR & \\
\hline & & $\begin{array}{l}\text { Gobiernos Autónomos Descentralizados municipales de Loja y } \\
\text { Catamayo }\end{array}$ & \\
\hline & & $\begin{array}{l}\text { Entidades públicas del gobierno nacional con jurisdicción } \\
\text { zonal, provincial, distrital: Coordinación Distrital de Educación; } \\
\text { Dirección Provincial del Ministerio de Transporte y Obras } \\
\text { Públicas; Dirección Provincial del Ministerio de Agricultura, } \\
\text { Ganadería, Silvicultura y Pesca; Dirección Provincial de la } \\
\text { Agencia de Aseguramiento del a Calidad del Agro; Empresa } \\
\text { Eléctrica Regional del Sur. }\end{array}$ & \\
\hline
\end{tabular}




\begin{tabular}{|l|l|l|c|}
\hline \multirow{4}{*}{$\begin{array}{l}\text { Actores } \\
\text { económicos }\end{array}$} & $\begin{array}{l}\text { Asociaciones (prestación de servicios, agricultores), pequeños } \\
\text { productores locales }\end{array}$ & 5 \\
\cline { 2 - 3 } & $\begin{array}{l}\text { Presidentes de barrios (Comités pro-mejoras y juntas de } \\
\text { desarrollo de barrio) }\end{array}$ & \\
& \multirow{3}{*}{ Actores sociales } & Comités de gestión de agua & \\
\cline { 3 - 4 } & Centros educativos beneficiados & 32 \\
\cline { 3 - 4 } & Comité de padres de familia de los centros educativos & \\
\hline \multicolumn{2}{|l|}{ Total de entrevistas } & &
\end{tabular}

Fuente: Elaboración propia a partir del trabajo de campo. Proyecto Energías Renovables y Desarrollo Local (Loja - Ecuador).

\section{RECOGIDA DE INFORMACIÓN Y TRATAMIENTO DEL DIS- CURSO DE LOS ACTORES A PARTIR DEL ANÁLISIS DE CON- TENIDOS}

\subsection{Estructura de la entrevista: preguntas de investigación y temas clave planteados}

La entrevista se ha diseñado en torno a un conjunto de temas y conceptos clave, que responden a las preguntas de investigación, y que son resultado de la revisión bibliográfica, documentación referente a la política pública estudiada, el PDTC y el análisis de casos de estudio relacionados (Munday et al., 2011; Delicado et al., 2016). El resultado es un modelo de entrevista semiestructurada cuyo fin es la recogida de información primaria, que permita a su vez, por un lado, obtener descripciones, explicaciones y posicionamientos respecto a los procesos de desarrollo local vinculados con la central eólica; y, por otro, valorar cualitativamente su potencial, limitaciones y beneficios para la comunidad local, siempre desde las perspectivas de los diferentes actores (Anexo 1). La secuencia de preguntas de la entrevista aborda los temas clave, pero también tienen cabida otras que pueden incluirse en el transcurso de la misma, bien para profundizar sobre algunas de las cuestiones planteadas o bien para abordar cuestiones nuevas relevantes que han ido apareciendo y que el entrevistador introduce, atendiendo a su interés y a los conocimientos y disponibilidad del entrevistado (Kvale, 2011).

La entrevista se inicia con preguntas generales sobre la situación del territorio y sus habitantes. A partir de ahí se divide en dos secciones. En la primera se recogen aspectos relacionados con la valoración de los efectos directos de la presencia de la central en el territorio (positivos o negativos), mientras que en la segunda se analizan las actuaciones que forman parte del PDTC (Anexo 1).

Respecto de la primera parte, tres son las grandes cuestiones que se plantean. En primer lugar, como se ha señalado, las energías renovables son, en términos generales, socialmente aceptadas y positivamente percibidas por sus beneficios ambientales (Ribeiro et al., 2014; IRENA, 2017). Sin embargo, es necesario 
conocer qué sucede a nivel local, y aquí suele señalarse que las necesidades constructivas y las características tecnológicas de los parques eólicos pueden tener impactos negativos en el ambiente y en el paisaje del territorio en el que se asientan (Frolova y Pérez Pérez, 2008; Groth y Vogt, 2014; Dai et al., 2015). Por tanto, interesa la valoración y posicionamiento de los actores locales respecto de la presencia de la central y de sus efectos en la zona de influencia, positivos y negativos. En segundo lugar, se pregunta sobre cómo la central eólica afecta a la calidad de vida de la población local, y en concreto los efectos esperados en cuanto al acceso y mejora del servicio eléctrico y la creación de empleo local (Burguillo y del Río, 2008; Okkonen y Lehtonen, 2016; IRENA, 2017).

En tercer y último lugar, con el objeto de comprender y analizar los efectos que tiene la presencia del parque eólico en las dinámicas económicas y productivas en el territorio de influencia, se aborda el concepto clave de las energías renovables como elemento de desarrollo económico del medio rural, desde dos perspectivas. Por un lado, si la central ha propiciado el fortalecimiento de otras actividades económicas a partir de los bienes y servicios que se demandan para su construcción, es decir, si esta está siendo capaz de generar encadenamientos productivos que mejoren las capacidades locales y favorezcan, en su caso, la creación de empleo en la zona de influencia. Por otro lado, si otras actividades económicas pueden verse debilitadas, o fortalecidas, por la presencia de la central, como por ejemplo el sector turístico o las actividades de ocio en el área.

En la segunda parte de la entrevista se tratan cuatro grandes aspectos relacionados con las actuaciones que forman parte del PDTC. El primero es el impacto del PDTC sobre la calidad de vida de la población (Buen Vivir), dado que cubrir las carencias en cuanto a dotación de infraestructuras y servicios básicos habría de ser una condición necesaria, aunque no suficiente, para la mejora de la calidad de vida (SENPLADES, 2013) y el desarrollo local sostenible (Burguillo y del Río, 2008). El segundo aspecto trata los efectos del PDTC sobre las dinámicas productivas y el potencial a que éste pueda estar dando lugar a medio y largo plazo. El tercer aspecto se refiere al modelo de gestión y el entorno institucional, y en qué medida este favorece, por un lado, los objetivos de desarrollo de la zona de influencia de la central y, por otro, las propias actuaciones del PDTC (es bien conocida la importancia que los entornos institucionales locales tienen como catalizadores y, en algunos casos, obstaculizadores, de los procesos de desarrollo local). El último aspecto hace referencia a la dimensión social, y en concreto al proceso de empoderamiento de la sociedad local a través de su participación en el diseño e implementación del PDTC. El interés e importancia de esta dimensión social radica en que la organización e integración social, el empoderamiento y la participación ciudadana, contribuyen al fortalecimiento de las capacidades individuales y colectivas, ayudan a generar confianza en la población y permiten consolidar las estructuras organizativas comunitarias a través del diálogo interno y la interacción con los demás actores (principalmente locales).

Finalmente, el modelo de entrevista se completa con una serie de preguntas cerradas, centradas en las mejoras o cambios detectados por los entrevistados en los diferentes barrios y el impacto sobre la vida de la población local (con opcio- 
nes tales como si se vive mejor, si hay más seguridad, más visitantes, mayores y mejores accesos, empleo para los vecinos, o disponibilidad de equipamientos, caso de los lugares de reunión). Las respuestas a estas preguntas contribuyen a cuantificar, categorizar los temas específicos que en ellas se abordan, pero también a validar las valoraciones de los entrevistados respecto de las obras ejecutadas en la zona de influencia (mejorando la fiabilidad de la información obtenida en apartados anteriores). Es decir, el contraste entre el discurso y las preguntas cerradas permite detectar (en tiempo real o, en su caso, volviendo a contactar con el entrevistado) inconsistencias, de manera que el entrevistador tiene la oportunidad de volver sobre el tema en cuestión para aclarar las cuestiones menos claras sobre el discurso o posiciones del entrevistado.

\subsection{Construcción del sistema de categorías y codificación de la infor- mación}

Partiendo de los temas clave y de las preguntas de la entrevista, se han definido ocho grandes categorías de contenidos (Cuadro 3). En primer lugar, tenemos la referida a "población y territorio", que recoge las valoraciones sobre la situación actual de la zona de estudio y su población. En segundo lugar, la categoría "energía eólica", en la que se incluyen las percepciones sobre la energía eólica en general, y sobre la central Villonaco en particular. Ambas categorías, a priori, ayudarán a sistematizar la visión de los actores sobre la zona de estudio, así como sus percepciones respecto de la puesta en marcha y operación de la central eólica en su territorio.

\section{Cuadro 3. Sistema de categorías}

\begin{tabular}{|c|c|}
\hline Temas de la entrevista & Categorías obtenidas \\
\hline Realidad actual de la zona de influencia (preguntas introductorias) & Población y territorio \\
\hline $\begin{array}{l}\text { Percepción de los actores respecto a la central eólica: } \\
\text { Aceptación social (beneficios)/Oposición (impactos negativos). }\end{array}$ & Energía eólica \\
\hline $\begin{array}{l}\text { Energías renovables como elemento de desarrollo económico del } \\
\text { medio rural. }\end{array}$ & \multirow{2}{*}{ Desarrollo Económico } \\
\hline $\begin{array}{l}\text { Desarrollo productivo: mejora de la producción, sostenibilidad, } \\
\text { formación. }\end{array}$ & \\
\hline $\begin{array}{l}\text { Percepción de los actores respecto a la central eólica: } \\
\text { Aceptación social (beneficios)/Oposición (impactos negativos). }\end{array}$ & Medio Ambiente \\
\hline $\begin{array}{l}\text { Capacidades de la ciudadanía: } \\
\text { Participación, organización e integración social, empoderamiento. }\end{array}$ & $\begin{array}{l}\text { Organización } \\
\text { Dinámica Social }\end{array}$ \\
\hline Desarrollo territorial (o desarrollo local) & Desarrollo Territorial \\
\hline
\end{tabular}




\begin{tabular}{|l|l|}
\hline $\begin{array}{l}\text { Efectos esperados en la calidad de vida de la población: } \\
\text { Acceso y mejora del servicio eléctrico (mejora de otros servicios) y } \\
\text { creación de empleo local: } \\
\text { tipo y duración. }\end{array}$ & \\
\hline $\begin{array}{l}\text { Buen Vivir: } \\
\text { Calidad de vida de la población, inclusión social (PDTC) }\end{array}$ & Buen Vivir \\
\hline $\begin{array}{l}\text { Gestión institucional del PDTC: } \\
\text { Descentralización, capacidad institucional, cooperación } \\
\text { interinstitucional, problemas y limitaciones. }\end{array}$ & Sistema institucional \\
\hline
\end{tabular}

Fuente: Elaboración propia a partir de las preguntas de investigación y la estructura de la entrevista. Proyecto Energías Renovables y Desarrollo Local (Loja - Ecuador).

Las siguientes tres categorías permiten clasificar la información de la construcción y operación de la central, así como de la implementación del PDTC. Estas son "desarrollo económico", "medio ambiente" y "organización y dinámica social". Sin embargo, estas no son suficientes si se quiere analizar el desarrollo desde el punto de vista del territorio, y por ello se añade otra categoría, el "desarrollo territorial". El Buen Vivir se plantea como otra categoría importante, dado que esta constituye una perspectiva asociada a la calidad de vida de la población local (SENPLADES, 2013), en este caso a partir de la construcción y operación de la central. Finalmente se define también como categoría analítica el "sistema institucional", que incluye las valoraciones sobre la gestión de las instituciones públicas en todo lo referido a los procesos de desarrollo local en el área de estudio.

Estas categorías configuran el sistema básico de códigos. No obstante, las valoraciones de los actores permiten profundizar con más detalle, y por ello es posible completarlo con diferentes subcódigos (subcategorías, o subtemas), obtenidos a partir de las preguntas planteadas en la entrevista, así como las explicaciones e ideas complementarias que aportan los actores entrevistados. El resultado es un sistema de ocho categorías y 74 subcategorías o subcódigos (Cuadro 4) que constituyen la base para desarrollar el proceso de análisis e interpretación de la información (Kvale, 2011). A partir de definición de la tipología de temáticas, organizada en categorías y subcategorías, se inicia la fase de codificación, una de las más importantes del análisis de la información primaria. Consiste básicamente en la asignación de cada segmento de texto a uno o varios subcódigos o códigos (VERBI SOFTWARE, 2015). 


\section{Cuadro 4. Sistema de códigos y subcódigos elaborado para el análisis de la información}

\begin{tabular}{|c|c|c|c|c|}
\hline Cód. & $\begin{array}{l}\text { Pob l a c i ó n } \\
\text { Territorio }\end{array}$ & $\begin{array}{l}\text { D e s a r r o l l o } \\
\text { Económico }\end{array}$ & $\begin{array}{l}\text { Organización y } \\
\text { Dinámica Social }\end{array}$ & Buen Vivir \\
\hline 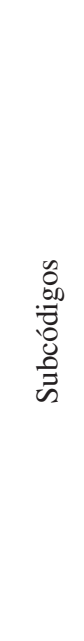 & $\begin{array}{l}\text { Perspectivas de } \\
\text { futuro } \\
\text { Otras problemáticas } \\
\text { Vinculación } \\
\text { administraciones } \\
\text { Desatención } \\
\text { administraciones } \\
\text { Autoestima } \\
\text { Necesidades básicas } \\
\text { Sectores productivos } \\
\text { Percepción de } \\
\text { beneficios } \\
\text { Epoderamiento } \\
\text { Capital Social } \\
\text { Zona de influencia } \\
\text { Clientelismo } \\
\text { Factores limitantes } \\
\text { Potencialidades } \\
\text { territorio }\end{array}$ & $\begin{array}{l}\text { Financiación } \\
\text { Negocios locales } \\
\text { Proyectos a } \\
\text { futuro } \\
\text { Comercialización } \\
\text { productos } \\
\text { Turismo (y ocio) } \\
\text { Desarrollo } \\
\text { agropecuario } \\
\text { Emprendimiento } \\
\text { local } \\
\text { Economía } \\
\text { popular y } \\
\text { solidaria } \\
\text { Generación de } \\
\text { empleo }\end{array}$ & $\begin{array}{l}\text { Redes sociales } \\
\text { Asociacionismo } \\
\text { Formación } \\
\text { Procesos } \\
\text { participativos } \\
\text { Capital Social } \\
\text { Motivación } \\
\text { colectiva } \\
\text { Liderazgos } \\
\text { comunitarios } \\
\text { Organización } \\
\text { barrial }\end{array}$ & $\begin{array}{l}\text { Derechos } \\
\text { Medio ambiente } \\
\text { Infraestructura } \\
\text { comunitaria } \\
\text { Seguridad } \\
\text { Salud } \\
\text { Educación } \\
\text { Infraestructuras } \\
\text { básicas } \\
\text { Transporte público } \\
\text { Infraestructura vial } \\
\text { Alcantarillado } \\
\text { Agua potable } \\
\text { Electrificación } \\
\text { Desarrollo de } \\
\text { capacidades } \\
\text { Buen Vivir }\end{array}$ \\
\hline Cód. & Energía Eólica & Medio Ambiente & $\begin{array}{l}\text { Desarrollo } \\
\text { Territorial }\end{array}$ & $\begin{array}{l}\text { Sistema } \\
\text { Institucional }\end{array}$ \\
\hline 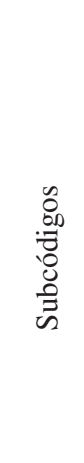 & $\begin{array}{l}\text { Motivación } \\
\text { Matriz energética } \\
\text { Compensación } \\
\text { Generación de } \\
\text { electricidad } \\
\text { Generación de } \\
\text { conocimientos } \\
\text { Aporte ambiental } \\
\text { Percepción población }\end{array}$ & $\begin{array}{l}\text { Plan manejo } \\
\text { ambiental } \\
\text { Reparación de } \\
\text { daños } \\
\text { Impactos } \\
\text { negativos } \\
\text { Concienciación } \\
\text { ambiental } \\
\text { Aporte ambiental }\end{array}$ & $\begin{array}{l}\text { Desarrollo } \\
\text { endógeno } \\
\text { Nivel de } \\
\text { ruralidad } \\
\text { Matriz } \\
\text { productiva } \\
\text { Buen Vivir } \\
\text { Limitaciones } \\
\text { Priorización } \\
\text { necesidades } \\
\text { PDTC } \\
\text { Política } \\
\text { energética }\end{array}$ & $\begin{array}{l}\text { Proximidad } \\
\text { población } \\
\text { Limitaciones } \\
\text { entidades públicas } \\
\text { Inversión/ } \\
\text { Financiación } \\
\text { Competencias } \\
\text { Paternalismo } \\
\text { Relaciones } \\
\text { interinstitucionales } \\
\text { GAD Provincial } \\
\text { GAD Municipal } \\
\text { CELEC EP } \\
\text { GENSUR }\end{array}$ \\
\hline
\end{tabular}

Fuente: Elaboración propia a partir de las preguntas de investigación, cuestionario y del trabajo de campo. Proyecto Energías Renovables y Desarrollo Local (Loja - Ecuador).

Aunque la tarea de vincular cada fragmento de texto con las diferentes categorías obviamente es decisión del investigador, las funciones de esta herramienta facilitan el proceso (Kuckartz, 2014). A modo de ejemplo, se puede examinar una entrevista en la que se resalta un determinado segmento de texto, al que se ha asignado el código o códigos y, en su caso, subcódigos, que tienen relación 
con el tema que se menciona en dicho fragmento (Figura 3).

Como resultado de la codificación los segmentos de texto han quedado organizados en una estructura que, basada en una clara conexión entre los fragmentos y las categorías, permite el análisis sistemático de la información (VERBI SOFTWARE, 2015). Hasta aquí, el resultado del proceso de categorización y codificación resulta muy útil para realizar una descripción detallada de la zona de estudio, los actores y su tipología, las intervenciones realizadas en el territorio y sus principales resultados, etc. Sin embargo, es necesario un análisis más detallado, que permita llevar a cabo interpretaciones de carácter cualitativo, y para ello se han de detectar las conexiones y relaciones entre los diferentes elementos.

Figura 3. Codificación de la información con MAXQDA

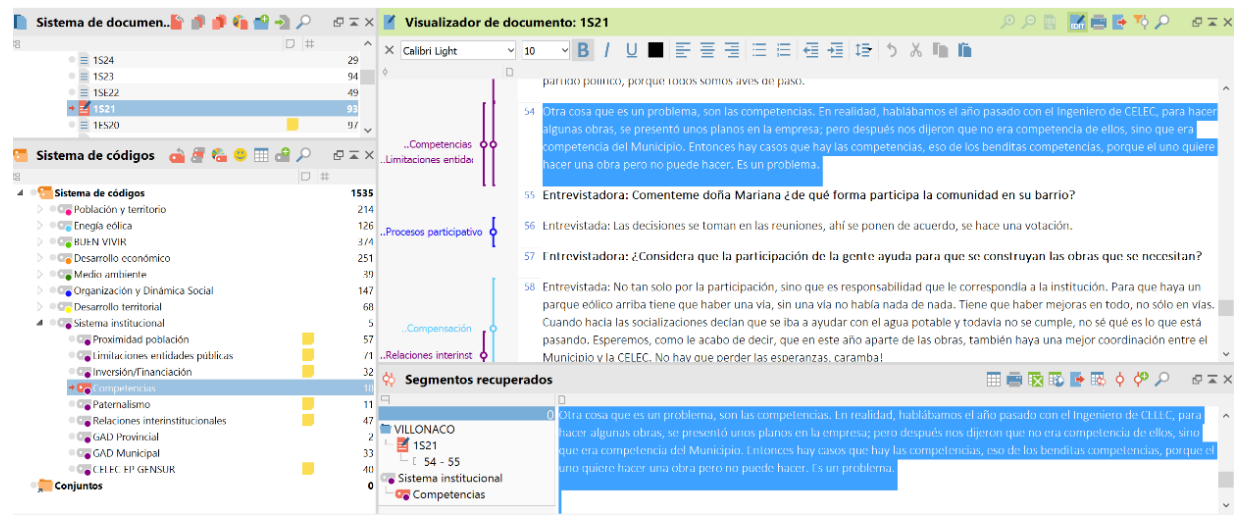

Fuente: Elaboración propia a partir del trabajo de campo. Proyecto Energías Renovables y Desarrollo Local (Loja - Ecuador).

\section{RESULTADOS Y DISCUSIÓN: CRITERIOS Y HERRAMIENTAS PARA EL ANÁLISIS DE LA INFORMACIÓN}

En el apartado anterior se ha definido la estructura temática en la que se organizan los contenidos, en este caso a partir del discurso de los actores. Esa tipología o estructura de códigos y subcódigos supone una cierta simplificación, pero permite organizar tales contenidos de forma que la aproximación al discurso de los actores resulte más clarificadora.

Tres son las aproximaciones de cara al análisis de contenidos. En primer lugar, la valoración del peso e importancia de cada temática o subtemática, (a través de los códigos y subcódigos en los que se estructuran tales contenidos). En este caso la valoración puede llevarse a cabo para cada uno de los actores individuales, para agrupamientos de estos (en función de criterios o atributos tales como edad, sexo, territorio -barrios en este caso-, sector económico, perfil socioprofesional, etc.), o bien para el conjunto de los actores. Este primer análisis permite caracterizar con cierta precisión los contenidos en los diferentes discursos, 
así como una aproximación a la percepción y posición de los actores o grupos de actores en el marco de los procesos de desarrollo local que se pretenden estudiar. En segundo lugar, el estudio de las relaciones entre temáticas o subtemáticas, que puede abordarse analizando la proximidad entre estas a lo largo del discurso de los actores, o bien a partir de su concurrencia (conexiones que el entrevistado establece entre temas). En tercer y último lugar, para los casos en los que sea de especial interés el análisis de contenidos de un discurso o entrevista específico, se dispone de una herramienta complementaria, el "retrato del documento". Este permite visualizar la amplitud de cada temática (tiempo dedicado a ella) y su distribución a lo largo del discurso (abordaje más o menos fragmentado o coherente, recurrencia a la misma a lo largo del discurso, etc.). En los apartados siguientes se muestran ejemplos de estas tres aproximaciones a partir de algunos resultados obtenidos en el caso de estudio.

\subsection{Análisis de contenidos: Tipología y relevancia de las temáticas en el discurso de los actores}

La codificación constituye la base para el análisis sistemático de los discursos contenidos en las entrevistas. Permite, en primer lugar, caracterizarlos en función de las temáticas predominantes, identificando los temas o aspectos centrales en el discurso de cada actor o grupo de actores; y, en segundo lugar, valorar qué posición adopta el actor o actores respecto de ese tema. Con frecuencia ambos aspectos van unidos, y el planteamiento de un tema suele llevar aparejada una determinada posición. Hay varias aproximaciones posibles en función de con qué información se trabaje, cómo se organice y cuál sea su tratamiento (Cuadro 5).

Cuadro 5. Posibilidades de organización y tratamiento de la información (1)

\begin{tabular}{|c|c|c|c|c|c|c|}
\hline & & \multicolumn{5}{|c|}{ B) Frecuencia } \\
\hline & & \multicolumn{3}{|c|}{ b.1) Segmentos de texto } & \multicolumn{2}{|c|}{ b.2) Entrevista } \\
\hline & & $\begin{array}{l}\text { b.1.1) por } \\
\text { entrevista } \\
\text { individual }\end{array}$ & $\begin{array}{l}\text { b.1.2) por } \\
\text { grupos de } \\
\text { entrevistas } \\
\text { (ej. según } \\
\text { actores) }\end{array}$ & $\begin{array}{l}\text { b.1.3) por } \\
\text { total de } \\
\text { entrevistas }\end{array}$ & $\begin{array}{l}\text { b.2.1) por } \\
\text { total de } \\
\text { entrevistas }\end{array}$ & $\begin{array}{l}\text { b.2.2) por } \\
\text { grupos de } \\
\text { entrevistas }\end{array}$ \\
\hline \multirow{2}{*}{$\begin{array}{l}\text { A) Nivel de } \\
\text { detalle en el } \\
\text { sistema de } \\
\text { codificación }\end{array}$} & $\begin{array}{l}\text { a.1) Tema o } \\
\text { Categoría } \\
\text { ( código) }\end{array}$ & 1 & 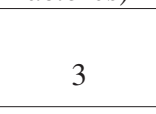 & 5 & 7 & 9 \\
\hline & $\begin{array}{l}\text { a.2) Subtema o } \\
\text { subcategoría } \\
(\approx \text { subcódigo })\end{array}$ & 2 & 4 & 6 & 8 & 10 \\
\hline
\end{tabular}


El investigador puede trabajar con varios niveles de detalle en el sistema de codificación (A), por temas (a.1), con lo que se tiene una visión global de la estructura temática (ocho temas en el caso de estudio), y/o por subtemas (a.2), descendiendo a un nivel de detalle mucho mayor (74 subtemas en el caso de estudio). Ambos niveles son complementarios en el proceso de investigación social, pero ha de ser el investigador el que decida cuál es el idóneo en cada caso.

El paso siguiente consiste en detectar qué temas y subtemas están presentes, y en qué medida, en cada discurso (B). Para ello hay dos grandes formas de organizar y tratar la información, con ventajas e inconvenientes. Por un lado, se puede trabajar a nivel de segmento de texto (b.1), es decir, contabilizando la frecuencia o número de segmentos de texto que se corresponden con cada tema o subtema. Aunque este enfoque es bastante frecuente en investigación social, los resultados han de interpretarse con prudencia, sobre todo cuando se trabaja con una única entrevista o cuando se pretenden extraer conclusiones determinantes con datos muy detallados (casos 1 y 2 del Cuadro 5). En este sentido ha de tenerse claro que una mayor frecuencia de segmentos de texto sobre un tema, no implica que éste sea más importante para el actor en cuestión. En este caso cabría hablar únicamente de "amplitud" de ese tema (es decir, tiempo dedicado al mismo por el entrevistado). No obstante, la fiabilidad mejora a medida que aumenta el número de entrevistas (casos 3 a 6). Incluso con detalle temático, pero trabajando con un conjunto de entrevistas (casos 4 y 6) ya es posible obtener una buena aproximación al peso que los diferentes aspectos (subtemas) tienen en el discurso de los actores.

Adicionalmente, para añadir confianza a los resultados, puede llevarse a cabo alguna prueba estadística (por ejemplo, $\mathrm{Chi}^{2}$ ) que informe sobre el grado de significación estadística de la distribución resultante. Cuando esas diferencias no resultan significativas (tanto para la distribución por subtemas como para temas), o el investigador no desea asumir riesgos ponderando la importancia de cada tema en función de la frecuencia de segmentos, se tiene la opción de sustituirla por un valor unitario igual para cada entrevista o discurso en el que aparece un determinado tema (b.2). Por tanto, en este caso el resultado es independiente del número de segmentos (casos 7 al 10), aunque también se puede optar por un tratamiento de la información por grupos de entrevistas, si el interés radica en comparar el peso que tienen los diferentes temas y subtemas en el discurso de cada grupo de actores, por la frecuencia de entrevistas en que aparecen (casos 9 y 10). Obviamente ambos procedimientos pueden utilizarse de forma complementaria, trabajando a nivel de temas o subtemas en función de las necesidades y posibilidades que ofrezca la información.

Es importante, por tanto, que el investigador mantenga abiertas todas las posibilidades de explotación y tratamiento, para lo cual la codificación ha de haberse realizado con rigor metodológico y conceptual. Dos ejemplos a partir del caso de estudio permiten ver algunas de las potencialidades y limitaciones de las ocho posibilidades de tratamiento. La primera aproximación se puede obtener en el nivel más genérico (se correspondería con el caso número 7 del Cuadro 5), en el que, por un lado, se trabaja con la clasificación de los contenidos temáticos en 
ocho grandes temas y, por otro, se valora únicamente la presencia o ausencia de cada uno de ellos en las diferentes entrevistas (independientemente de la amplitud del discurso sobre el mismo) (Figura 4).

Figura 4. Número de entrevistas que abordan cada tema y segmentos por tema (1)

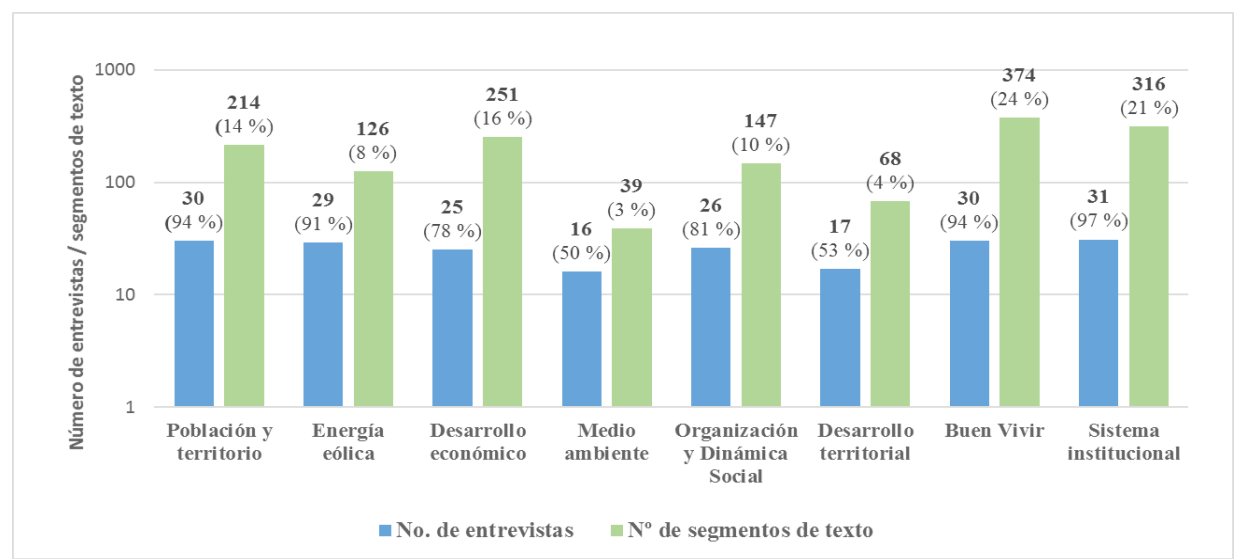

(1): Junto a los valores absolutos se incluye el porcentaje de entrevistas en las que se aborda cada tema $(n=32)$, y el porcentaje de segmentos de texto asignados a cada tema, del conjunto de entrevistas $(\mathrm{n}=1535, \Sigma=100 \%)$.

Fuente: Elaboración propia a partir del trabajo de campo. Proyecto Energías Renovables y Desarrollo Local (Loja - Ecuador).

Los resultados de la Figura 4 permiten ver, como primera aproximación, que determinados temas son abordados por la mayor parte de actores (población, energía, Buen Vivir y sistema institucional), mientras que, en el extremo opuesto, otros temas son abordados por apenas la mitad de los actores entrevistados (desarrollo territorial y medio ambiente). Manteniendo la fiabilidad, es posible desagregar estos resultados por grupos de actores, como puede verse en el Cuadro 6. Algunos temas son abordados por la totalidad de los actores de al menos dos de los grupos (población y territorio, energía eólica, Buen Vivir y sistema institucional), mientras que otros claramente siguen siendo los menos abordados (desarrollo territorial, medio ambiente), probablemente porque son conceptos poco familiares para ciertos grupos de actores. 


\section{Cuadro 6. Proporción de entrevistas en las que abordan cada uno de los temas por grupos de actores (1)}

\begin{tabular}{|l|c|c|c|}
\hline \multicolumn{1}{|c|}{ Temas o Categorías } & $\begin{array}{c}\text { Actores } \\
\text { institucionales }\end{array}$ & $\begin{array}{c}\text { Actores } \\
\text { sociales }\end{array}$ & $\begin{array}{c}\text { Actores } \\
\text { económicos }\end{array}$ \\
\hline Población y territorio & $83 \%$ & $100 \%$ & $100 \%$ \\
\hline Energía eólica & $75 \%$ & $100 \%$ & $100 \%$ \\
\hline Desarrollo económico & $75 \%$ & $73 \%$ & $100 \%$ \\
\hline Medio ambiente & $8 \%$ & $67 \%$ & $100 \%$ \\
\hline Organización y Dinámica Social & $58 \%$ & $100 \%$ & $80 \%$ \\
\hline Desarrollo territorial & $67 \%$ & $47 \%$ & $40 \%$ \\
\hline Buen Vivir & $83 \%$ & $100 \%$ & $100 \%$ \\
\hline Sistema institucional & $100 \%$ & $100 \%$ & $80 \%$ \\
\hline
\end{tabular}

(1): Caso número 9 del Cuadro 5

Fuente: Elaboración propia a partir del trabajo de campo. Proyecto Energías Renovables y Desarrollo Local (Loja - Ecuador).

En función de los objetivos de la investigación, la aproximación anterior (presencia de los diferentes temas en el discurso de los actores), podría resultar excesivamente genérica. No obstante, si se quiere mantener la entrevista como unidad de referencia, una opción es pasar de los temas a los subtemas (se estaría en el caso número 10 del Cuadro 5). Esto permitiría diferenciar qué aspectos concretos (de los 74 subtemas) se abordan en cada una de las categorías y por parte de cada uno de los grupos de actores, precisando más y mejor el análisis de los diferentes discursos.

La otra opción es, como se ha señalado, trabajar por número de segmentos (tratamiento que no es recomendable con una única entrevista, e incluso para un número muy reducido, de 4-5 entrevistas). Si se analiza la distribución de segmentos de texto por temas, los resultados anteriores quedan confirmados (Figura 4, en la que se recogen los casos 7 y 5 del Cuadro 5), con una correlación bastante alta $(r=0,8$, siendo $\mathrm{p}=0,004)$. Pese a que en ambos casos se trabaja con la estructura temática, el tratamiento de la información es muy diferente, e implica costes igualmente diferentes (muy sencillo y rápido cuando el análisis se basa en la presencia o ausencia de un tema, y bastante más complejo y laborioso cuando se analizan los segmentos de texto).

Como se ha señalado, una adecuada codificación permite mayores posibilidades de tratamiento, a la vez que se mantiene la fiabilidad en los resultados y las interpretaciones que de ellos puedan derivarse. En este sentido, MAXQDA ofrece diferentes posibilidades de visualización y exploración de resultados. Así por ejemplo, la herramienta matriz de códigos permite la visualización a cualquier nivel de agregación (por un lado, por temas o subtemas y, por otro, de entrevistas individuales, grupos de entrevistas, o el conjunto de todas ellas). La Figura 5 presenta de forma gráfica la frecuencia de segmentos codificados para los tres grupos de actores (mayor cuanto mayor es el tamaño del nodo). De 
esta forma, la matriz gráfica permite una primera aproximación a lo que podría definirse como "importancia" que cada grupo de actores otorga a cada temática (al menos según se deduce de la amplitud de tales temáticas). Como puede observarse este nivel de detalle ya permite completar y precisar de manera significativa los resultados anteriores.

\section{Figura 5. "Importancia" de los diferentes temas (según frecuencia de seg- mentos de texto codificados) (1)}

\begin{tabular}{|c|c|c|c|}
\hline Sistema de códigos & Actores institucionales & Actores sociales & Actores económicos \\
\hline D Población y territorio & $\bullet$ & • & • \\
\hline D Enegía eólica & - & - & - \\
\hline Buen Vivir & - & 0 & ○ \\
\hline$D$ Desarrollo económico & $\bullet$ & $\bullet$ & O \\
\hline D. Medio ambiente & • & - & • \\
\hline D Organización y Dinámica Social & • & $\bullet$ & $\bullet$ \\
\hline$D$ Desarrollo territorial & $\bullet$ & - & - \\
\hline DSistema institucional & O & - & $\bullet$ \\
\hline$\sum$ SUMA & 428 & 813 & 294 \\
\hline
\end{tabular}

(1): Caso número 3 del Cuadro 5

Fuente: Elaboración propia a partir del trabajo de campo. Proyecto Energías Renovables y Desarrollo Local (Loja - Ecuador).

Un nivel de análisis bastante útil es el que tiene en cuenta únicamente la presencia o ausencia de segmentos de texto en cada subtema (pudiendo tener cada entrevista un valor de 0 ó 1 en cada uno de los subtemas). A esta nueva matriz se le denomina "matriz condensada". Tanto en su forma agregada, como si se desagrega por grupos de actores (Figura 6), presenta dos grandes ventajas en investigación social. En primer lugar, permite evitar posibles riesgos de sub/ sobre representación derivada de la frecuencia total de segmentos de texto y, en segundo lugar, se desciende al nivel de subtemas con fiabilidad y detalle analítico suficiente. Por tanto, en la matriz condensada lo que se valora es que el actor en cuestión conceda una relevancia mínima a cada subtema (que lo aborde al menos una vez). De esta forma los resultados son más precisos y representan mejor la situación real.

La Figura 6 presenta, a modo de ejemplo, los resultados correspondientes al tema Buen Vivir. En ella se observan variaciones significativas respecto de las anteriores, pues hay subtemas abordados por muy pocos o ninguno de los actores en cada grupo, mientras que aparecen tendencias claras respecto a la importancia que le otorgan uno u otro grupo de actores a unos determinados subtemas. Por tanto, es evidente que tanto por la elevada confianza que se deriva de este tipo de análisis (por ejemplo, no se trabajan frecuencias absolutas de segmentos de texto) como por el nivel de desagregación (se desciende a nivel de subtemas), la matriz condensada es una herramienta especialmente interesante en la investigación social en general, y en los procesos de desarrollo local a partir del análisis 
de contenidos del discurso de los actores, en particular.

En conclusión, el investigador social dispone de diferentes tratamientos, complementarios entre sí, con niveles de precisión diferentes a la hora de analizar la información. Trabajar con unos u otros dependerá de la información disponible, de las ventajas e inconvenientes de cada tratamiento y de los intereses del investigador.

\section{Figura 6. Importancia de los diferentes subtemas del tema Buen Vivir (ma- triz condensada) (1)}

\begin{tabular}{|c|c|c|c|c|}
\hline \multirow{2}{*}{$\begin{array}{l}\text { Sistema de códigos } \\
\triangle \text { BUEN VIVIR }\end{array}$} & \multirow[t]{2}{*}{ Actores institucionales } & \multirow[t]{2}{*}{ Actores sociales } & \multirow[t]{2}{*}{ Actores económicos } & \multirow{2}{*}{$\begin{array}{c}\text { SUMA } \\
0\end{array}$} \\
\hline & & & & \\
\hline Derechos & • & - & & 3 \\
\hline COMedio ambiente & & - & - & 4 \\
\hline - Infraestructura comunitaria & - & - & - & 5 \\
\hline Seguridad & - & - & - & 8 \\
\hline CSalud & - & - & - & 8 \\
\hline Educación & - & - & - & 17 \\
\hline - Infraestructuras básicas & 0 & - & - & 12 \\
\hline - Transporte público & - & - & - & 6 \\
\hline - Infraestructura vial & - & - & - & 16 \\
\hline - Alcantarillado & & - & & 4 \\
\hline - Agua potable & - & - & - & 10 \\
\hline Electrificación & - & - & - & 17 \\
\hline Desarrollo de capacidades & & - & - & 3 \\
\hline CBuen Vivir & 0 & O & 0 & 24 \\
\hline$\sum$ SUMA & 34 & 76 & 27 & 137 \\
\hline
\end{tabular}

(1): Caso número 10 del Cuadro 5

Fuente: Elaboración propia a partir del trabajo de campo. Proyecto Energías Renovables y Desarrollo Local (Loja - Ecuador).

\subsection{Relaciones entre las temáticas presentes en los discursos de los actores}

Otro de los aspectos importantes para el análisis de resultados es mostrar de qué manera los actores relacionan las temáticas presentes en sus discursos. MAXQDA dispone de dos formas de visualizar estas relaciones entre códigos, por cercanía (proximidad entre temas o subtemas a lo largo del discurso, útil para comprender las razones que motivan un determinado posicionamiento o reflexión en el discurso de los actores), o por concurrencia (argumentación conjunta de varios temas o subtemas, lo cual pone de relieve relaciones que pueden ser significativas en el análisis de los procesos de desarrollo local). Para ilustrar esta utilidad a continuación se presenta una matriz de concurrencia, mostrando cómo los diferentes grupos de actores relacionan el subtema Buen Vivir con los demás subtemas (Figura 7).

La Figura 7 permite detectar ciertas diferencias en cómo los actores relacionan las temáticas presentes en sus discursos. Así, por ejemplo, los actores institucionales plantean una estrecha relación entre el Buen Vivir y la electrificación, mientras que para los actores sociales y económicos las relaciones se establecen 
con otras temáticas, y además son significativamente más débiles.

Por tanto, el análisis de concurrencia temática aporta una primera aproximación a las relaciones (causales o no) entre conceptos y estructuras argumentales presentes en el discurso de los actores (Conde, 2009), que a su vez contribuyen a explicar mejor los procesos que se están analizando; adicionalmente, permite una visión comparada entre las posiciones y percepciones de los diferentes grupos de actores. En el caso de estudio, con el que se ejemplifican las potencialidades del análisis de contenidos en entrevistas a actores vinculados a procesos de desarrollo local, este enfoque analítico contribuye de manera significativa a entender, valorar y explicar los efectos de la central eólica en el territorio, así como de las actuaciones llevadas a cabo en su zona de influencia, tal como lo percibe la muestra de actores entrevistados.

\section{Figura 7. Relaciones de concurrencia entre el subtema Buen Vivir y otras temáticas (1)}

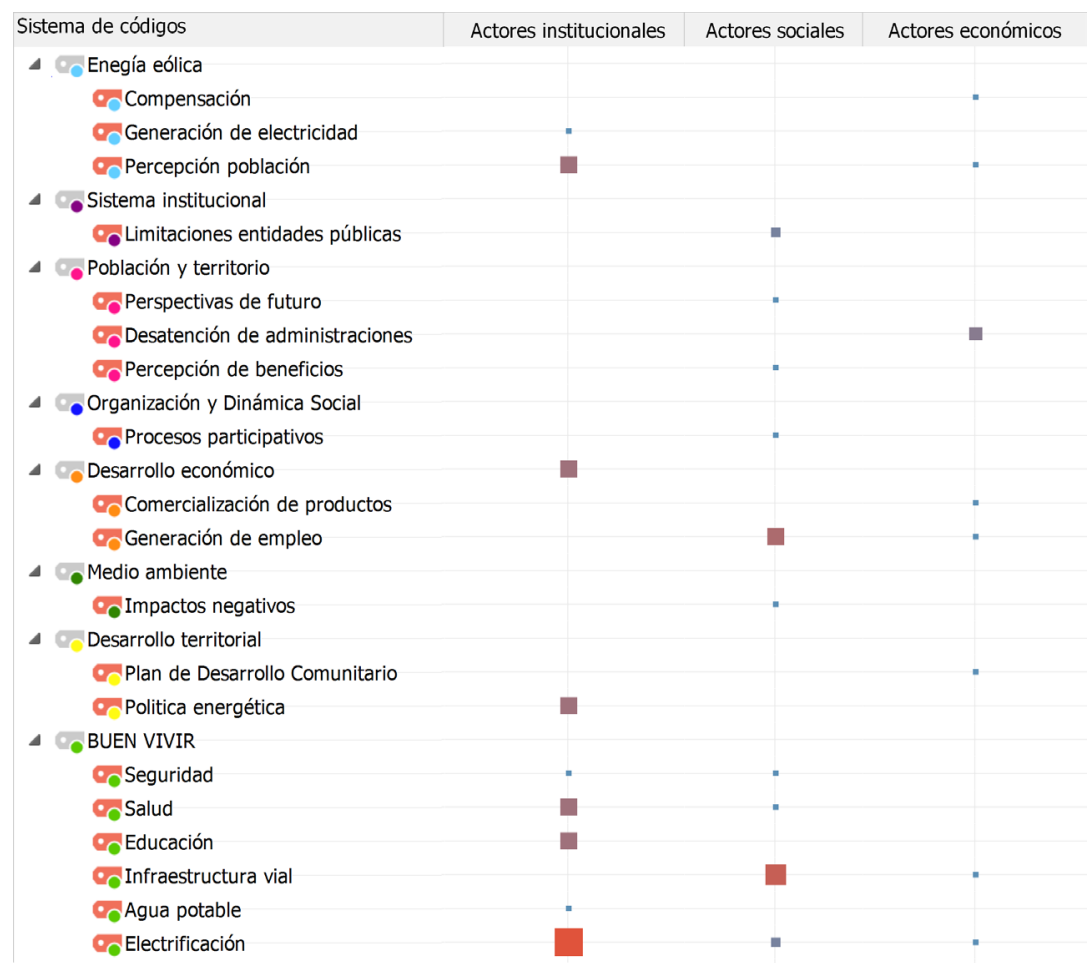

(1): La matriz de concurrencia presenta, para cada grupo de actores, todos los subcódigos cuyos segmentos de texto se solapan con el subcódigo Buen Vivir.

Fuente: Elaboración propia a partir de matrices individuales realizadas con MAXQDA. Proyecto Energías Renovables y Desarrollo Local (Loja - Ecuador). 


\subsection{La representación gráfica de la entrevista como herramienta de análisis}

Finalmente, a nivel de entrevista individual es posible profundizar en el análisis a partir de lo que en MAXQDA se denomina "retrato del documento". Este presenta de forma gráfica, por un lado, qué temas son los predominantes (amplitud que tiene cada uno de los temas o subtemas) y, por otro, cómo se organizan o distribuyen a lo largo del discurso del actor en cuestión. El resultado son dos gráficos complementarios (Figura 8), que permiten también visualizar cómo se articulan los diferentes temas a lo largo del discurso (teniendo en cuenta el momento de la entrevista en el que aparece un tema). El que sea aplicable únicamente a entrevistas individuales implica que, en su caso, es el investigador el que ha de llevar a cabo la comparación entre aquellos que resultan más significativos. Pese a esta limitación sigue siendo una herramienta muy útil tanto para análisis individuales como comparados.

En la Figura 8 (a) se observa cómo el texto codificado con el código sistema institucional (púrpura) aparece varias veces y en distintos momentos de la entrevista; es decir, es un tema al que el entrevistado acude con frecuencia, ya sea para tratarlo de manera individual o para ponerlo en relación con otros temas. Igualmente, el código medio ambiente (verde oscuro) aparece en un solo momento de la entrevista, lo que pondría de relieve que el actor está poco familiarizado con él, o que le concede escasa relevancia en el marco de su argumentación. En definitiva, este mapa del documento permite una interesante aproximación a la estructura argumental de cada actor, aunque su utilidad es mucho mayor cuando se lleva a cabo el análisis comparativo de las estructuras discursivas o de contenidos de los diferentes actores.

Adicionalmente, si se ordena la información por códigos, el nuevo retrato (b) muestra el volumen del texto codificado correspondiente a cada código (color). Esta nueva imagen aporta una idea del peso relativo que cada tema tiene para el actor en cuestión, a tenor al menos de la extensión que le dedica en su discurso. Así, a partir de los códigos que en mayor medida están presentes (ocupan más volumen en el documento), puede inferirse que son elementos especialmente articuladores del discurso de un determinado actor.

En general, esta doble visualización de la estructura de los contenidos de una entrevista permite profundizar en el análisis y mejorar la comprensión del discurso de cada actor o grupo de actores, bien a través de un análisis individual o bien mediante la comparativa entre diferentes retratos de documento. En cualquier caso, y teniendo en cuenta esa utilidad, el investigador ha de ser cauto en la interpretación de los resultados obtenidos (por ejemplo, no infiriendo que una mayor extensión de uno de los temas, o subtemas, implica necesariamente que una mayor importancia, en términos absolutos, con respecto a otros que ocupan menor extensión), habiendo en todo momento de tener en cuenta que este tipo de análisis no dejan de constituir una aproximación de carácter exploratorio. 


\section{Figura 8. Retratos del documento (a: distribución de temas en el discurso; b: amplitud de cada tema en el conjunto del discurso)}

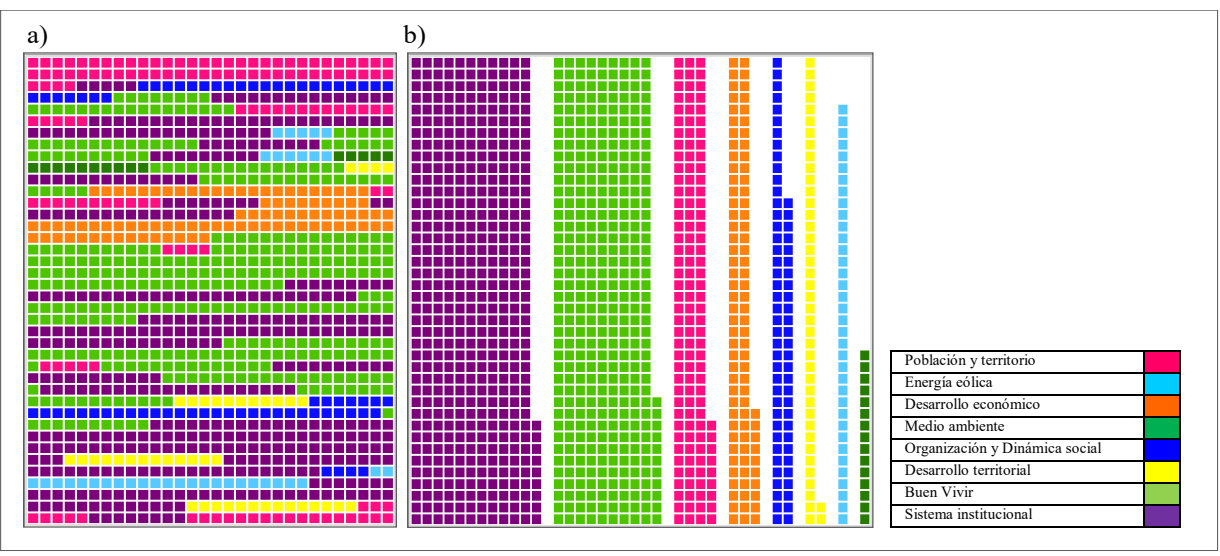

Fuente: Elaboración propia a partir del trabajo de campo. Proyecto Energías Renovables y Desarrollo Local (Loja - Ecuador). Actor Social 1S21.

\section{CONCLUSIONES}

A tenor de los análisis previos y de los resultados obtenidos, parece evidente que el análisis de contenidos a partir de las entrevistas a actores vinculados a procesos de desarrollo local, constituye una aproximación metodológica valiosa para el estudio de tales procesos. Su aplicación al caso de estudio de los efectos derivados de la puesta en marcha y operación de la central eólica Villonaco y el paralelo plan de desarrollo (PDTC), muestra que esta es una alternativa válida en la medida que permite, por un lado, abordar el estudio de este tipo de procesos locales desde la visión de los actores, como protagonistas de esos procesos. Y, por otro lado, permite, a través del análisis de los contenidos de sus discursos, valorar, comprender y explicar los efectos de las energías renovables en sus zonas de influencia.

Adicionalmente, en el caso de estudio se ha evidenciado la utilidad de esta perspectiva metodológica para abordar y analizar no solo los efectos esperados en el desarrollo local, como consecuencia de la construcción y operación de este tipo de centrales eléctricas, sino también de aquellos derivados de otras iniciativas como los Planes de Desarrollo Territorial vinculados a ellas. En este sentido, el análisis cualitativo de los contenidos de los discursos de los actores entrevistados permite valorar la incidencia de éstas nuevas estrategias de desarrollo local y la intervención de nuevos actores en las dinámicas territoriales.

Los resultados del análisis de la información permiten identificar la tipología de los discursos y valorar el posicionamiento y relevancia que cada grupo de actores le otorga a una determinada temática. Esto se ha logrado, primero a partir 
de la codificación de las entrevistas, y después, en base a un análisis exploratorio de resultados apoyado en distintos criterios; entre ellos están: la frecuencia de aparición de las distintas temáticas en el discurso de los actores (segmentos de texto codificados), la cantidad de entrevistas en la que aparece cada tema y la frecuencia en que aparece un determinado subcódigo (subtema) en la entrevista. La complementariedad de estos criterios permite identificar los aspectos concretos en torno a los cuales giran los discursos de los actores, y además el contraste de los resultados, que finalmente permiten determinar la importancia real que los entrevistados otorgan a las diferentes temáticas.

La aplicación de esta perspectiva metodológica además permite avanzar hacia la identificación de las relaciones entre las temáticas presentes en el discurso de los actores. En esta línea, el análisis de concurrencia resulta especialmente relevante en este tipo de estudios, para identificar relaciones significativas entre los diferentes aspectos presentes en el discurso de los entrevistados y los procesos y fenómenos estudiados.

El caso concreto presentado en este trabajo, en el que se muestra la organización y tratamiento de la información con un objetivo eminentemente metodológico, pretende ser, sobre todo, un ejemplo del potencial que tiene el enfoque metodológico del análisis de contenido del discurso de los actores, en el estudio de procesos de desarrollo local. A partir de aquí, para profundizar y enriquecer el análisis, se evidencia la necesidad, por un lado, de aplicar esta metodología a todo el sistema de actores; y por otro, de utilizar otras herramientas complementarias, como los resúmenes o las matrices cualitativas, que permitirán extraer conclusiones mucho más concretas.

Es evidente también que, por la validez y utilidad de este tipo de enfoque, basado en el análisis de contenidos a partir del discurso de actores (contenidos en nuestro caso en entrevistas semiestructuradas) es susceptible de aplicarse a situaciones muy diversas, en las que el investigador cuente con un texto en el que se refleje la visión de uno o, sobre todo, un relativamente elevado número de actores. Este último es el caso de un buen número de trabajos de investigación social, en los que las entrevistas constituyen una fuente de información primaria fundamental.

\section{BIBLIOGRAFÍA}

ALBERICH, T. (2014): “Redes Sociales y Planificación. La Investigación-Acción Participativa (IAP): Principios, fases y experiencias", en Planificación y gestión. Manual para la acción social, Madrid, Editorial Dykinson, pp. 117-145.

ALBERICH, T. et al. (2009): Metodologías Participativas. Manual, Madrid, Observatorio Internacional de Ciudadanía y Medio Ambiente Sostenible (CIMAS).

ALDUNATE, E. y CÓRDOBA, J. (2011): Formulación de programas con la metodología de marco lógico (Serie Manuales, núm. 68), Santiago de Chile, Instituto Latinoamericano y del Caribe de Planificación Económica y Social (ILPES). 
AROCENA, J. (2001): "Una investigación de procesos de desarrollo local”, en El desarrollo local: un desafío contemporáneo, Montevideo, Ediciones Santillana, Universidad Católica de Uruguay, pp. 201-229.

BARBOUR, R. (2013): Los grupos de discusión en Investigación Cualitativa, Madrid, Morata.

BLAU, P. y SCHWARTZ, J. (1984): Crosscutting Social Circles. Testing a Macrostructural Theory of Intergroup Relations, Orlando (FL), Academic Press.

BOURDIEU, P. (1989): "El espacio social y la génesis de las clases", Estudios sobre las Culturas Contemporáneas, III (7), pp. 27-55.

BURGUILLO, M. y DEL RÍO, P. (2008): “La contribución de las energías renovables al desarrollo rural sostenible en la Unión Europea: pautas teóricas para el análisis empírico", ICE Tribuna de Economía, 845, pp. 149-166.

CAMACHO, F. y ESPARCIA, J. (2014): "From social networks to discourse analysis in rural local development processes. A case study from N.W. of Murcia (Spain)". European Social Networks Conference, (Paper session: Social Networks and Local Development), Autonomous University of Barcelona, Barcelona, July 1-4, disponible en http://go.uv.es/8W0HM6N [consulta: 18-10-2017]

CONDE, F. (2009): Análisis sociológico del sistema de discursos (Colección Cuadernos Metodológicos, núm. 43), Madrid, CIS.

CORBIN, J. y STRAUSS A. (2015): Basics of Qualitative Research, Thousand Oaks (CA), Sage.

CRESWELL, J. (2014): Research Design. Qualitative, Quantitative and Mixed Methods, Thousand Oaks (CA), Sage.

DAI, K., BERGOT, A., LIANG, C., XIANG, W. y Huang, Z. (2015): "Environmental issues associated with wind energy - A review", Renewable Energy, 75, pp- 911-92.1

DELICADO, A., FIGUEIREDO, E., y SILVA, L. (2016): “Community perceptions of renewable energies in Portugal: Impacts on environment, landscape and local development", Energy Research \& Social Science, 13, pp. 84-93.

ESPARCIA, J. (2010): "El potencial del análisis de contenidos como metodología para la caracterización de los modelos conceptuales-relacionales del desarrollo rural en España”, Actas del XV Coloquio de Geografía Rural: Territorio, paisaje y patrimonio rural, Cáceres, Universidad de Extremadura, Servicio de Publicaciones, pp. 87101, disponible en http://go.uv.es/dO42BMX [consulta: 18-10-2017]

ESPARCIA, J., ESCRIBANO, J. y SERRANO, J. (2015): "From development to power relations and territorial governance: Increasing the leadership role of LEADER Local Action Groups in Spain", Journal of Rural Studies, 42, pp. 29-42.

FALS BORDA, O., y RODRÍGUEZ BRANDÃO, C. (1986): Investigación participativa, Montevideo, Instituto del Hombre y Ediciones de la Banda Oriental.

FAO (2005): Un enfoque para el desarrollo rural: Desarrollo territorial participativo negociado (DTPN), Organización de las Naciones Unidas para la Agricultura y la Alimentación (FAO).

FOUCAULT, M. (1978): La arqueología del saber, México, Siglo XXI Editores.

FROLOVA, M. y PÉREZ PÉREZ, B. (2008): "El desarrollo de las energías renovables y el paisaje: algunas bases para la implementación de la Convención Europea del Paisaje en la Política energética española”, Cuadernos Geográficos, 43, pp. 289-309.

GROTH, T.M., y VOGT, C. (2014): "Residents' perceptions of wind turbines: An analysis of two townships in Michigan", Energy Policy, 65, pp. 251-260.

HALFACREE, K., KOVÁCH, I. y WOODWARD, R. (2002): Leadership and Local Power in European Rural Development, Aldershot (England), Ashgate Publisher. 
IRENA (2017): Renewable energy benefits: Leveraging local capacity for onshore wind, Abu Dhabi, International Renewable Energy Agency (IRENA).

JUNKER, A. (2012): "Optimism and Caution Regarding New Tools for Analyzing Qualitative Data", Sociological Methodology 42, pp. 85-87.

KAEFER, F., ROPER, J. y SINHA, P. (2015): "A Software-Assisted Qualitative Content Analysis of News Articles: Example and Reflections", Forum: Qualitative Social Research, 16(2), Art. 8, 55 p.

KELLER, R. (2010): "El análisis del discurso basado en la sociología del conocimiento (ADSC). Un programa de investigación para el análisis de relaciones sociales y políticas de conocimiento", Forum: Qualitative Social Research, 11(3), Art. 5, 35 p.

KOHLBACHER, F. (2006): "The Use of Qualitative Content Analysis in Case Study Research", Forum: Qualitative Social Research, 7(1), Art. 21, 30 p.

KRAUSE, M. (1995): "La investigación cualitativa: Un campo de posibilidades y desafíos", Revista Temas de Educación, 7, pp. 19-39.

KRIPPENDORFF, K. (2004): Content Analysis: An Introduction to Its Methodology, Thousand Oaks (CA), Sage.

KUCKARTZ, U. (2014), Qualitative Text Analysis: A Guide to Methods, Practice and Using Software, London, Sage.

KU囚 SAILLARD, E. (2011): "Systematic Versus Interpretive Analysis with Two CAQDAS Packages: NVivo and MAXQDA”, Forum: Qualitative Social Research, 12(1), Art. 34, 75 p.

KVALE, S. (2011): Las entrevistas en Investigación Cualitativa (1a ed.), Madrid, Morata.

LIMA, J. L. y MANINI, P. M. (2016): "Metodología para el Análisis Cualitativo de Contenido integrado con la técnica de Mapas Mentales utilizando los softwares Nvivo y FreeMind", Informação \& Informação, 21(3), pp. 63-100.

MAYRING, P. (2000): "Qualitative Content Analysis", Forum: Qualitative Social Research, 1(2), Art. 20, 28 p.

MORGAN, D. (1997): Focus groups as qualitative research, Thousand Oaks, Sage.

MUNDAY, M., BRISTOW, G., y Cowell, R. (2011): "Wind farms in rural areas: How far do community benefits from wind farms represent a local economic development opportunity?", Journal of Rural Studies, 27(1), pp. 1-12.

OKKONEN, L., y LEHTONEN, O. (2016): "Socio-economic impacts of community wind power projects in Northern Scotland", Renewable Energy, 85, pp. 826-833.

PIÑUEL, J.L. (2002): "Epistemología, metodología y técnicas del análisis de contenido", Estudios de Sociolingüística 3(1), pp. 1-42.

RIBEIRO, F., FERREIRA, P., ARAÚJO, M., y BRAGA, A. C. (2014): "Public opinion on renewable energy technologies in Portugal", Energy, 69, pp. 39-50.

RUIZ, J.I. (2012): Teoría y práctica de la investigación cualitativa. Universidad de Deusto, Bilbao.

RUIZ RUIZ, J. (2009): “Análisis sociológico del discurso: métodos y lógicas”, Forum: Qualitative Social Research, 10(2), Art. 26, 32 p.

SENPLADES (2013): Plan Nacional para el Buen Vivir 2013-2017, Quito, Secretaría Nacional de Planificación y Desarrollo.

SILVER, C., y LEWINS, A. (2014): Using Software in Qualitative Research. A Step-byStep Guide, London, Sage.

STAMANN, C., JANSSEN, M. y SCHREIER, M. (2016): "Searching for the Core: Defining Qualitative Content Analysis", Forum: Qualitative Social Research, 17(3), Art. 16, 24 p. 
STEWART, D. y SHAMDASANI, P. (2015): Focus groups: Theory and practice. Thousand Oaks, Sage.

TAYLOR, S., BOGDAN, R. y DEVAULT, M. (2016): Introduction to Qualitative Research Methods: A Guidebook and Resource, Hoboken (NJ), John Wiley \& Sons.

VALLES, M. S. (2014): Entrevistas cualitativas (Colección Cuadernos Metodológicos, núm. 32), Madrid, CIS.

VERBI SOFTWARE (2015): MAXQDA 12 Reference Manual (v1.0), disponible en http://www.maxqda.com/download/manuals/MAX12 manual eng.pdf [consulta: 03-10-2016]

VERD, J.M. y LOZARES, C. (2016): Introducción a la investigación cualitativa. Fases, métodos y técnicas, Madrid, Ed. Síntesis.

VILLASANTE, T.R. (2007): "Una articulación metodológica: desde textos del Socioanálisis, I(A)P, F. Praxis, Evelyn F. Keller, Boaventura S. Santos, etc.”, Política y Sociedad, 44(1), pp. 141-157.

- (2015): "Para Avanzar con las Metodologías Participativas, Usando la 'Socio-Praxis' (Epílogo)", en De Sur a Norte: metodologías participativas desde la sociopraxis, São Borja (RS), Faith, pp. 177-179.

VILLASANTE, T.R., MONTAÑ́́S, M., MARTÍ, J. (2000): La Investigación Social Participativa (Colección Construyendo Ciudadanía, núm. 1), Barcelona, Ediciones El Viejo Topo.

WHITE, M.J., JUDD, M.D., POLIANDRI, S. (2012): "Illumination with a Dim Bulb? What do social scientists learn by employing qualitative data analysis software (QDAS) in the service of multi-method designs?", Sociological Methodology, 42(1), pp. 43-76.

YANG, A., ROUNSEVELL, M., HAGGETT, C., PIORR, A. y WILSON, R. (2015): "The Use of Spatial Econometrics, Stakeholder Analysis and Qualitative Methodologies in The Evaluation of Rural Development Policy", Journal of Environmental Assessment Policy and Management, 17(2), pp. 1-33. 


\section{Anexo No 1}

\section{Estructura de la entrevista: Valoración de los efectos de la central eólica Villonaco y el PDTC en el territorio}

\begin{tabular}{|c|c|c|c|}
\hline & $\begin{array}{l}\text { Preguntas de } \\
\text { investigación }\end{array}$ & $\begin{array}{l}\text { Temas y conceptos } \\
\text { clave }\end{array}$ & Preguntas de la entrevista \\
\hline \multirow{3}{*}{$\begin{array}{l}\mathbf{p} \\
\mathbf{A} \\
\mathbf{R} \\
\mathbf{T} \\
\mathbf{E} \\
\mathbf{1}\end{array}$} & $\begin{array}{l}\text { ¿La central eólica } \\
\text { genera impactos } \\
\text { positivos / negativos } \\
\text { en la zona de } \\
\text { influencia? }\end{array}$ & $\begin{array}{l}\text { Percepción de los } \\
\text { actores respecto a la } \\
\text { central eólica: } \\
\text { - Aceptación social } \\
\text { (beneficios). } \\
\text { - Oposición } \\
\text { (impactos } \\
\text { negativos). }\end{array}$ & $\begin{array}{l}\text { - ¿Cuál es su opinión acerca de la } \\
\text { central eólica Villonaco? } \\
\text { - ¿Cuál fue la actitud de la gente del } \\
\text { barrio frente a la idea de construir } \\
\text { una central eólica en el Villonaco? } \\
\text { - ¿La central tiene impactos } \\
\text { positivos/negativos en la zona de } \\
\text { influencia? } \\
\text { - ¿Considera que en el contexto de } \\
\text { la construcción de la central ha } \\
\text { existido armonía entre desarrollo } \\
\text { económico, desarrollo social y } \\
\text { respeto al medio ambiente? }\end{array}$ \\
\hline & $\begin{array}{l}\text { ¿De qué manera la } \\
\text { central eólica mejora/ } \\
\text { afecta la calidad de } \\
\text { vida de la población } \\
\text { local? }\end{array}$ & $\begin{array}{l}\text { Efectos esperados en } \\
\text { la calidad de vida de } \\
\text { la población: } \\
\text { - Acceso y mejora del } \\
\text { servicio eléctrico } \\
\text { (mejora de otros } \\
\text { servicios). } \\
\text { - Creación de } \\
\text { empleo local: tipo y } \\
\text { duración. }\end{array}$ & $\begin{array}{l}\text { - A partir de que la central eólica } \\
\text { entró en funcionamiento, ¿ha } \\
\text { mejorado claramente el servicio de } \\
\text { energía eléctrica para la población } \\
\text { del barrio? } \\
\text { - ¿La central generó/genera puestos } \\
\text { de trabajo para los vecinos? ¿Qué } \\
\text { tipo de trabajo realizan/realizaban? } \\
\text { - ¿Aún trabajan en la central? } \\
\text { - ¿De qué otra forma ha cambiado la } \\
\text { presencia de la central su vida en } \\
\text { particular? }\end{array}$ \\
\hline & $\begin{array}{l}\text { ¿Promueve el parque } \\
\text { eólico Villonaco un } \\
\text { mayor dinamismo } \\
\text { económico y } \\
\text { productivo? }\end{array}$ & $\begin{array}{l}\text { Energías renovables } \\
\text { como elemento de } \\
\text { desarrollo económico } \\
\text { del medio rural. }\end{array}$ & $\begin{array}{l}\text { - ¿Cómo describiría usted los } \\
\text { beneficios que tiene la central eólica } \\
\text { para la economía local? } \\
\text { - ¿La central ha atraído/disminuido el } \\
\text { turismo? } \\
\text { - ¿Los vecinos se benefician del } \\
\text { turismo que ha atraído la central? }\end{array}$ \\
\hline
\end{tabular}




\begin{tabular}{|c|c|c|c|}
\hline & & $\begin{array}{l}\text { Buen Vivir: } \\
\text { Calidad de vida de la } \\
\text { población, inclusión } \\
\text { social }\end{array}$ & $\begin{array}{l}\text { - ¿Cuál es su apreciación respecto } \\
\text { al impacto que tienen estas } \\
\text { actuaciones sobre la calidad de vida } \\
\text { de la población local? } \\
\text { - En relación a su vida diaria, ¿cree } \\
\text { que ha mejorado de alguna manera } \\
\text { desde que se ejecutaron estas obras? } \\
\text { - ¿Qué tan importante es esta mejora } \\
\text { en su forma de vida? }\end{array}$ \\
\hline $\begin{array}{l}\mathbf{P} \\
\mathbf{A} \\
\mathbf{R} \\
\mathbf{T} \\
\mathbf{E}\end{array}$ & $\begin{array}{l}\text { ¿Ha generado el } \\
\text { PDTC condiciones } \\
\text { para el desarrollo } \\
\text { territorial de la zona } \\
\text { de influencia? }\end{array}$ & $\begin{array}{l}\text { Desarrollo productivo: } \\
\text { Mejora de la } \\
\text { producción, } \\
\text { sostenibilidad, } \\
\text { formación. }\end{array}$ & $\begin{array}{l}\text { - ¿Podría describir cómo usted o } \\
\text { su empresa se ha beneficiado por } \\
\text { las acciones para el desarrollo } \\
\text { productivo de la zona de influencia } \\
\text { de la central Villonaco? } \\
\text { - ¿Cuál es su apreciación respecto } \\
\text { al impacto que tienen estas } \\
\text { actuaciones sobre la economía } \\
\text { local? } \\
\text { - ¿Qué cambios se han producido } \\
\text { en las actividades productivas a } \\
\text { partir de la implementación de estas } \\
\text { actuaciones? } \\
\text { - ¿De qué manera han intervenido los } \\
\text { actores institucionales y privados en } \\
\text { el eje de desarrollo productivo de } \\
\text { este Plan? } \\
\text { - ¿Han surgido nuevos actores } \\
\text { económicos como efecto de las } \\
\text { intervenciones para el desarrollo } \\
\text { productivo? ¿Se han fortalecido los } \\
\text { existentes? }\end{array}$ \\
\hline
\end{tabular}




\begin{tabular}{|c|c|c|c|}
\hline $\begin{array}{l}\mathbf{P} \\
\mathbf{A} \\
\mathbf{R} \\
\mathbf{T} \\
\mathbf{E}\end{array}$ & $\begin{array}{l}\text { ¿Ha favorecido el } \\
\text { PDTC el desarrollo } \\
\text { de procesos } \\
\text { participativos de la } \\
\text { población? }\end{array}$ & $\begin{array}{l}\text { Capacidades de la } \\
\text { ciudadanía: } \\
\text { Participación, } \\
\text { organización e } \\
\text { integración social, } \\
\text { empoderamiento. }\end{array}$ & $\begin{array}{l}\text { - ¿La elaboración e implementación } \\
\text { del Plan de Desarrollo Territorial } \\
\text { contó con la participación de la } \\
\text { comunidad? } \\
\text { - ¿Podría describir ese proceso de } \\
\text { participación? } \\
\text { - ¿Se ha tomado en cuenta la opinión } \\
\text { de la población a la hora de decidir } \\
\text { qué obras eran más importantes (o } \\
\text { urgentes) y por tanto habría que } \\
\text { realizar primero? } \\
\text { - ¿Considera usted que estos procesos } \\
\text { han fortalecido la confianza de la } \\
\text { población beneficiaria para impulsar } \\
\text { cambios positivos en la zona? }\end{array}$ \\
\hline & $\begin{array}{l}\text { ¿Es este modelo de } \\
\text { gestión favorable para } \\
\text { alcanzar los objetivos } \\
\text { de desarrollo de la } \\
\text { zona de influencia de } \\
\text { la central eólica? }\end{array}$ & $\begin{array}{l}\text { Gestión institucional } \\
\text { del PDTC: } \\
\text { Descentralización, } \\
\text { capacidad } \\
\text { institucional, } \\
\text { cooperación } \\
\text { interinstitucional, } \\
\text { problemas y } \\
\text { limitaciones. }\end{array}$ & $\begin{array}{l}\text { - ¿Cómo se ha planificado y } \\
\text { ejecutado esta obra? } \\
\text { - Para llevar a cabo estas } \\
\text { intervenciones, ¿ha existido un } \\
\text { trabajo coordinado de las entidades } \\
\text { involucradas? } \\
\text { - ¿Podría describir como ha sido ésta } \\
\text { relación interinstitucional? } \\
\text { - ¿Qué aspectos han limitado la } \\
\text { ejecución del Plan? }\end{array}$ \\
\hline
\end{tabular}

Fuente: Elaboración propia a partir del trabajo de campo y Kvale, 2011:87. Proyecto Energías Renovables y Desarrollo Local (Loja - Ecuador). 
